\title{
Title: Persistent influence of obliquity on ice-age terminations since the Middle Pleistocene Transition
}

\begin{abstract}
Authors: Petra Bajo ${ }^{1,2,3}$, Russell N. Drysdale ${ }^{1,4 *}$, Jon D. Woodhead ${ }^{5}$, John C. Hellstrom ${ }^{5}$, David Hodell $^{6}$, Patrizia Ferretti ${ }^{7,8}$, Antje H.L. Voelker ${ }^{9,10}$, Giovanni Zanchetta ${ }^{11}$, Teresa Rodrigues ${ }^{9,10}$, Eric Wolff $^{6}$, Jonathan Tyler ${ }^{12}$, Silvia Frisia ${ }^{13}$, Christoph Spötl ${ }^{14}$, Anthony E. Fallick ${ }^{15}$
\end{abstract}

\section{Affiliations:}

${ }^{1}$ School of Geography, University of Melbourne, Carlton, Victoria 3053, Australia.

${ }^{2}$ Australian Nuclear Science and Technology Organisation, Lucas Heights, NSW 2234, Australia.

${ }^{3}$ Croatian Geological Survey, Milana Sachsa 2, Zagreb, Croatia

${ }^{4}$ Laboratoire EDYTEM - UMR5204, Université de Savoie Mont Blanc, 73376 Le Bourget du Lac, France.

${ }^{5}$ School of Earth Sciences, University of Melbourne, Parkville, Victoria 3010, Australia.

${ }^{6}$ Department of Earth Sciences, University of Cambridge, Cambridge CB2 3EQ, UK.

${ }^{7}$ Istituto per la Dinamica dei Processi Ambientali, Consiglio Nazionale delle Ricerche (IDPA-CNR), Venice 30172, Italy.

${ }^{8}$ Dipartimento di Scienze Ambientali, Informatica e Statistica, Università Ca' Foscari, Venice 30172, Italy

${ }^{9}$ Instituto Português do Mar e da Atmosfera (IPMA), Divisão de Geologia e Georecursos Marinhos, 1495-006 Lisbon, Portugal.

${ }^{10}$ Centre of Marine Sciences (CCMAR), University of the Algarve, 8005-139 Faro, Portugal

${ }^{111}$ Department of Earth Sciences, University of Pisa, Pisa 56100, Italy.

${ }^{12}$ Department of Earth Sciences, University of Adelaide, North Terrace, South Australia, 5005, Australia 
Science Submitted Manuscript: Confidential

МlAAAS

$27{ }^{13}$ School of Environmental and Life Sciences, University of Newcastle, Callaghan 2308, NSW, 28 Australia.

$29{ }^{14}$ Institute of Geology, University of Innsbruck, 6020 Innsbruck, Austria.

$30 \quad{ }^{15}$ Scottish Universities Environmental Research Centre, East Kilbride G75 0QF, Scotland, UK.

31

$32 *$ Corresponding author: $\underline{\text { rnd@unimelb.edu.au }}$

33

34

35 
37 Abstract:

38 Radiometric dating of glacial terminations over the last 640,000 years suggests pacing by Earth's 39 precession, with each glacial-interglacial spanning four or five $\sim 20$-kyr cycles. However, the lack of 40 firm age estimates for older Pleistocene terminations confounds attempts to test the persistence of 41 precession forcing. We combine an Italian speleothem record anchored by a U-Pb chronology with 42 North Atlantic ocean data to show that the first two deglaciations of the so-called $\sim 100$-kyr world are 43 separated by two obliquity cycles, with each termination starting at the same high phase of obliquity 44 but at opposing phases of precession. An assessment of 11 radiometrically dated terminations spanning 45 the last million years suggests obliquity exerted a persistent influence on not only their initiation but 46 also their duration.

49 Earth's obliquity played a key role in the initiation and duration of glacial terminations over the last 50 million years. 
Main Text:

A major challenge of testing the orbital (Milankovitch) theory of the ice ages is the uncertainty associated with the chronology of marine records. Orbital solutions are very accurate over the Pleistocene (1) but the age profile of deep-ocean sediments, where much of the evidence for global ice-volume changes is preserved, often has large errors. Astronomical tuning of ocean records renders any test of the Milankovitch hypothesis invalid because of circular logic. Testing theories of orbital forcing ultimately requires ocean-sediment records firmly anchored in absolute time.

A poorly understood feature of Pleistocene glacial-interglacial (G-IG) cycles is the change in the period of terminations - the relatively rapid switches from glacial to interglacial climate - during the Middle Pleistocene Transition (MPT) 1.25 to 0.7 million years ago (Ma) (2-6). Evidence from ocean sediments shows that most terminations occurred every $\sim 40,000$ years (40 kyr) prior to the MPT, but averaged $\sim 100 \mathrm{kyr}$ in the post-MPT interval (5). Although the precise mechanisms for this switch remain unclear (4-6), recent studies highlight the critical interval of Marine Isotope Stages (MIS) 2422 , when major changes in ocean circulation and ice-sheet dynamics occurred $(7,8)$. This interval includes a 'failed termination' at the MIS 24-23 transition, the residual ice from which probably contributed to the step-like increase in global ice volume observed over the subsequent MIS 22 glacial (the '900-ka event') (5, 9). Accordingly, the interval bounded by the MIS 26-25 and MIS 22-21 transitions - Terminations XII and X (TXII and TX) - is often erroneously considered to be the first '100-kyr cycle' (7).

The transition to the '100-kyr world' occurred without significant shifts in astronomical parameters $(4,8)$, implying that internal forcing changed the way the Earth system responded to orbital variations. and drove the climate to a state of mostly longer, more intense glaciations $(4,6,9)$. The $\sim 40-\mathrm{kyr}$ period for pre-MPT G-IG cycles suggests pacing by changes in Earth's axial tilt, or obliquity $(1,10)$, which 
affects the degree of seasonality in a given year. At high obliquity, the polar latitudes in both hemispheres receive more summer insolation, potentially inducing significant ice-sheet ablation (11). The dominance of a $\sim 100$-kyr periodicity for post-MPT terminations has been linked to forcing by changes in Earth's eccentricity $(1,12)$, but each $\sim 100$-kyr interval is more likely a cluster of precession (8) and/or obliquity $(13,14)$ cycles whose sum averages to $\sim 100 \mathrm{kyr}$ when viewed over the long term. This is supported by an Asian monsoon speleothem record spanning all terminations since $640 \mathrm{kyr}$ (15), which shows a spacing of four or five precession cycles. Precisely what happened in terms of forcing between the MPT and TVII ( $\sim 635 \mathrm{ka})$ remains unclear, yet the answer may assist in our understanding of the MPT itself.

Studies focusing on G-IG cycles that traverse the MPT $(8,13)$ have relied on stacked records of deepocean benthic oxygen isotope $\left(\delta^{18} \mathrm{O}\right)$ changes $(4)$, which are driven primarily by variations in global ice volume (10) but which also record a significant deep-ocean temperature component ( 6 ). Given the inability to directly date marine sediments beyond the limits of radiocarbon dating, and the phase uncertainties between the benthic ice-volume-proxy record and astronomical (or other) tuning targets, precisely datable archives are required. We independently determined the age of terminations across the MPT by tying the radiometric chronology from a speleothem $\delta^{18} \mathrm{O}$ time series to North Atlantic ocean-sediment records. We then compared our results with astronomical (10) and insolation parameters $(8,17)$ for terminations since $640 \mathrm{ka}(15,16)$.

Our speleothem record comes from Corchia Cave (Alpi Apuane, Italy; 19, 20) and spans the interval $\sim 970$ to $\sim 810 \mathrm{ka}$, encompassing two complete terminations (TXII and TX) and one uncompleted termination $(6,8)$. A composite $\delta^{18} \mathrm{O}$ time series derived from four stalagmites $(\mathrm{CC} 8, \mathrm{CC} 30, \mathrm{CC} 119$ and $\mathrm{CC} 122$ ) and a subaqueous speleothem (CD3) (Fig. 1) was anchored in absolute time using the U$\mathrm{Pb}$ method $(18,20-22)$ (fig. $\mathrm{S} 1$ and $\mathrm{S} 2$; Table $\mathrm{S} 1)$. Almost the entire record is replicated, and 
104

concordance between both the individual stalagmite age models (fig. S3a) and the overlapping stableisotope profiles (fig. S4a) allows all $\mathrm{U}-\mathrm{Pb}$ ages to be placed onto a common depth scale to produce a composite age-depth model $(19,22)$ (fig. S3b). After accounting for all sources of random and correlated uncertainties (22), the average model-age precision over the whole record is less than $7 \mathrm{kyr}$ ( $95 \%$ confidence interval) (fig. S3c).

The climate at Corchia Cave has strong teleconnections with circulation changes in the North Atlantic $(18,23)$, from where well-resolved marine records of glacial terminations have emerged $(24,25)$. Previous studies have shown that Corchia speleothem $\delta^{18} \mathrm{O}$ tracks changes in sea-surface temperature (SST) recorded off the Iberian margin $(19,26)$ through the effect of changes in SST on moisture advection to, and ultimately rainfall amount above, the cave site. However, during terminations, the link between regional SST and speleothem $\delta^{18} \mathrm{O}$ is overridden by large decreases in the $\delta^{18} \mathrm{O}$ of surface ocean water $\left(\delta^{18} \mathrm{O}_{\mathrm{sw}}\right)$ caused by collapse of continental ice sheets $(18)$. This flux of low $\delta^{18} \mathrm{O}$ values introduces a 'source effect' that is captured in rainfall $\delta^{18} \mathrm{O}$ at the cave, then recorded in its speleothems (27). Similar to speleothems, the $\delta^{18} \mathrm{O}$ of planktic foraminifera from the Iberian margin and the western Mediterranean Sea is also sensitive to changes in both SST and $\delta^{18} \mathrm{O}_{\mathrm{sw}}$. SST dominates the signal except during times of large meltwater incursions, such as terminations (23, 24, 27-29), making the planktic $\delta^{18} \mathrm{O}$ a robust tuning target for synchronizing the cave and ocean records (18). Accordingly, we tied our speleothem chronology to a new, high-resolution ocean-sediment record from North Atlantic Integrated Ocean Drilling Program (IODP) Site U1385 (30) by synchronizing the planktic $\delta^{18} \mathrm{O}$ to the Corchia $\delta^{18} \mathrm{O}$ time series (Fig. 1; ref 18, fig. S4b - S6, Table S2). Previous cores from this drilling site (23) register the commencement of terminations as large decreases in benthic $\delta^{18} \mathrm{O}$. This can be tested by comparing the phasing of these decreases with changes in planktic $\delta^{18} \mathrm{O}$ and the tetraunsaturated alkenone $\left(\mathrm{C}_{37: 4}\right)$ meltwater proxy from the same core, together with changes in SST at IODP Site U1387, nearby in the Gulf of Cadiz (fig. S5). 
The multi-proxy ocean data show that the commencement of large, near-monotonic benthic $\delta^{18} \mathrm{O}$ decreases for both terminations is approximately synchronous with rapid SST cooling and increased $\% \mathrm{C}_{37: 4}$ (Fig. 2) caused by meltwater from ice-sheet collapse reaching the Iberian margin. These terminal stadial events provide unequivocal evidence for the onset of the two terminations, as is the case with younger terminations recorded at the Iberian margin $(23,29)$. The larger $C_{37: 4}$ value witnessed during TX relative to TXII is consistent with the concurrent planktic $\delta^{18} \mathrm{O}$ decrease and SST cooling at the beginning of the termination, suggesting release of a larger meltwater volume (Fig. 2). This caused a significant decoupling between SST and planktic $\delta^{18} \mathrm{O}$, similar to that observed during TII $(23,25,29)$.

Applying the Corchia chronology to both ocean records allows the onset of TXII and TX to be dated with a precision of $\sim 0.5 \%$, with TXII starting at $960.1 \pm 4.7 \mathrm{ka}$ and TX at $875.4 \pm 4.7 \mathrm{ka}$ (Fig. 2). The corresponding LR04 benthic stack onset ages for TXII and TX suggest an intervening interval of 92kyr duration (Fig. 1d). Our new chronology yields a somewhat shorter interval of $\sim 85$ kyr (Fig. 2), constituting the first radiometric evidence that the period between TXII and TX represents a single GIG spanning $\sim$ two obliquity and $\sim$ four precession cycles. The chronology also reveals that both terminations started at similar phases of high obliquity, whereas the corresponding precession phases are almost diametrically opposed (Fig. 2). Furthermore, the two terminations were completed at $(\mathrm{NH})$ summer insolation and a very rapid termination. The more prolonged TX started at maximum precession but was completed at near maximum and minimum phases of obliquity and precession different rates (Fig. 1c). At TXII, ice-sheet collapse was initiated as both obliquity and precession approached maximum and minimum values respectively, resulting in strong Northern Hemisphere respectively (Fig. 2). These observations suggest that insolation changes more closely associated with 
153

obliquity than precession initiated the two terminations, whilst insolation status at this time controlled termination duration.

We now explore whether these relationships hold for TVII to TI, from which previous assessments favor precession over obliquity $(15,16)$. Estimates for their timing can be determined using a principle similar to our approach for TXII and TX. The precisely dated Chinese speleothems to which the younger terminations are anchored register perturbations to the Asian monsoon at the onset of a terminal stadial event $(15,16)$, enabling the start of each termination to be tied to a radiometric chronology (18, Table S3; fig. S7). Our analysis of all 11 radiometrically constrained terminations shows that the phasing of precession and obliquity at the start of TXII and TX falls within the range of values for post-MPT terminations (Fig. 3a, right panel). However, there is a clear obliquity phase lead (of at least $\sim 30$ degrees - Table S4; 18) for eight of the 11 terminations (Fig. 3b, c). Seven terminations began when integrated summer energy $>275 \mathrm{~W} / \mathrm{m}^{2}$ at $65^{\circ} \mathrm{N}$ (predominantly obliquity driven) (17) was above average (Fig. 3d), whereas $\mathrm{NH}$ summer insolation intensity at $65^{\circ} \mathrm{N}$ (predominantly precession driven) was below average in eight cases (Fig. 3e). A similar finding emerges for the termination midpoints, the classical metric for quantifying termination pacing (4): these midpoints are, overall, positioned at a closer proximity to maximum integrated summer energy values (Fig. 3d) than maximum NH summer insolation intensity values (Fig. 3e). We also find that the interval between each termination midpoint is a multiple of both precession ( $23 \pm 2 \mathrm{kyr})$ and obliquity periods $(\sim 41 \pm 7 \mathrm{kyr})$ (Table S4; 18). Finally, terminations never commenced in a precession cycle that does not align with the rising limb or peak of an obliquity cycle (Fig. 3b, c). Taking this evidence together, a predominance of precession over obliquity seems unlikely in the pacing of post-MPT terminations $(15,16)$. Obliquity has clearly played an equal, if not greater, role in their timing. 
We also determined the age at the end of each termination to calculate the time it took for each one to run to completion (18). We find that duration is significantly correlated with caloric summer half-year energy ( equal contributions from obliquity and precession), integrated summer energy and $\mathrm{NH}$ summer insolation intensity (all at $65^{\circ} \mathrm{N}$; Fig. 3f) at the commencement of a termination; the correlation with the precession index is much weaker but is remains significant for tilt. This reinforces the strong role of obliquity in post-MPT terminations.

Finally, the radiometrically constrained ensemble of 11 terminations allows us to evaluate the findings of a recent study implicating a combination of obliquity and precession in controlling termination timing over the last $1 \mathrm{Ma}(13)$. In this study, the age of each termination was estimated from the rate of change in benthic $\delta^{18} \mathrm{O}$ based on a depth-derived age model of the LR04 stack, providing an approximate age of each termination midpoint (13). It is argued that the $\sim 100-\mathrm{kyr}$ G-IG spacing consists of clusters of two $(80-\mathrm{kyr})$ or three $(\sim 120-\mathrm{kyr})$ tilt cycles $(13,14)$, with the interval between each termination controlled by obliquity but the exact timing within a given cycle occurring when the Earth is at perihelion during the NH summer solstice (13). Our results show that the spacing of termination midpoints is consistent with obliquity forcing (Fig. 3b; Fig. 4a, c), and that the midpoints are most consistently aligned with peaks in an insolation forcing metric (almost identical to caloric summer half-year insolation at $65^{\circ} \mathrm{N}$ ) which integrates approximately equal amounts of obliquity and precession (Fig. 4a-c) $(13,18)$.

New radiometric ages for TXII and TX coupled with a reassessment of well-dated younger terminations (TVII to TI) suggest that obliquity pacing of G-IG cycles continued beyond the 40-kyr world (7). A termination onset was more likely to occur at a higher phase of obliquity than precession. Once ice-sheet collapse was initiated, insolation changes driven by both precession and obliquity propelled the climate towards full interglacial conditions but at a rate according to the prevailing levels 
DIAAAS

of predominantly obliquity-controlled summer energy. As a final note, the results presented here imply that the term '100-kyr world' is both inaccurate and misleading, and its usage should probably be discontinued.

\section{References and Notes:}

1. A. Berger, M.F. Loutre. Insolation values for the climate of the last 10 million years. Quat. Sci. Rev.10, 297-317 (1991).

2. J.D. Hays, J. Imbrie, N.J. Shackleton. Variations in the Earth's orbit: Pacemaker of the ice ages. Science 194, 1121- (1976).

3. N.G. Pisias, T.C. Moore Jr. The evolution of Pleistocene climate: a time series approach. Earth Planet. Sci. Lett. 52, 450- (1981).

4. P.U. Clark et al. The middle Pleistocene transition: characteristics, mechanisms, and implications for long-term changes in atmospheric $\mathrm{pCO}_{2}$. Quat. Sci. Rev. 25, 3150-3184 (2006).

5. L.E. Lisiecki, M.E. Raymo. A Pliocene-Pleistocene stack of 57 globally distributed benthic $\delta^{18} \mathrm{O}$ records. Paleocean. 20, PA1003, doi:10.1029/2004PA001071 (2005).

6. M.J. Head, P.L. Gibbard. Early-Middle Pleistocene transitions: linking terrestrial and marine realms. Quatern. Int. 389, 7-46 (2015).

7. H. Elderfield et al. Evolution of ocean temperature and ice volume through the midPleistocene climate transition. Science 337, 704-709 (2012).

8. L.D. Pena, S.L. Goldstein. Thermohaline circulation crisis and impacts during the midPleistocene transition. Science 345, 318-322 (2014). 
9. P.C. Tzedakis, M. Crucifix, T. Mitsui, E.W. Wolff. A simple rule to determine which insolation cycles lead to interglacials. Nature 542, 427-432 (2017).

10. N.J. Shackleton, N.D. Opdyke. Oxygen-isotope and paleomagnetic stratigraphy of Pacific core V28-239 Late Pliocene to Latest Pleistocene. Mem., Geol. Soc. Am. 145, 449-464 (1976).

11. P. Huybers, C. Wunsch. Obliquity pacing of the late Pleistocene glacial terminations. Nature 434, 491-494 (2005).

12. L.E. Lisiecki. Links between eccentricity forcing and the 100,000-year glacial cycle. Nat. Geosci. 3, 349-352 (2010).

13. P. Huybers. Combined obliquity and precession pacing of late Pleistocene deglaciations. Nature 480, 229-232 (2011).

14. P. Huybers. Glacial variability over the last two million years: an extended depth-derived age model, continuous obliquity pacing, and the Pleistocene progression. Quat. Sci. Rev. 26, 3755 (2007).

15. H. Cheng et al. The Asian monsoon over the past 640,000 years and ice age terminations. Nature 534, 640-646 (2016).

16. H. Cheng et al. Ice age terminations. Science 326, 248-252 (2009).

17. P. Huybers. Early Pleistocene glacial gycles and the integrated summer insolation forcing. Science 313, 508-511 (2006).

18. See supplementary materials.

19. R.N. Drysdale et al. Palaeoclimatic implications of the growth history and stable isotope $\left(\delta^{18} \mathrm{O}\right.$ and $\left.\delta^{13} \mathrm{C}\right)$ geochemistry of a Middle to Late Pleistocene stalagmite from centralwestern Italy. Earth Planet. Sci. Lett. 227, 215-229 (2004). 
20. J. Woodhead et al. U-Pb geochronology of speleothems by MC-ICPMS. Quat. Geochronol. 1, 208-221 (2006).

21. J. Woodhead et al. $\mathrm{U}$ and $\mathrm{Pb}$ variability in older speleothems and strategies for their chronology. Quat. Geochronol. 14, 105-114 (2012).

22. P. Bajo, R. Drysdale, J. Woodhead, J. Hellstrom, G. Zanchetta. High-resolution U-Pb dating of an Early Pleistocene stalagmite from Corchia Cave (central Italy). Quat. Geochronol. 14, 5-17 (2012).

23. Tzedakis, P.C. et al. Enhanced climate instability in the North Atlantic and S Europe during the Last Interglacial. Nat. Commun.9, 4235, DOI: 10.1038/s41467-018-06683-3 (2018).

24. B. Martrat et al. Four climate cycles of recurring deep and surface water destabilizations on the Iberian margin. Science 317, 502-507 (2007).

25. I. Hernandez-Almeida, F.J. Sierro, I. Cacho, J.A. Flores. Impact of suborbital climate changes in the North Atlantic on ice sheet dynamics at the Mid-Pleistocene Transition. Paleoceanography 27, PA3214 (2012), doi.org/10.1029/2011PA002209.

26. R.N. Drysdale et al. Evidence for obliquity forcing of glacial termination II. Science 325, 1527-1531 (2009).

27. G. Marino et al. Bipolar seesaw control on last interglacial sea level. Nature 522, 197-201 (2015).

28. B. Martrat et al. Abrupt temperature changes in the Western Mediterranean over the past 250,000 years. Science 306, 1762-1765 (2004).

29. B. Martrat, P. Jiminez-Amat, R. Zahn, J.O. Grimalt. Similarities and dissimilarities between the last two deglaciations and interglaciations in the North Atlantic region. Quat. Sci. Rev. 99, 122-134 (2014). 
MIAAAS

30. D. Hodell et al. Shackleton Site Project Members. A reference time scale for Site U1385 (Shackleton Site) on the SW Iberian Margin. Global. Planet. Change 133, 49-64 (2015). 31. T. Rodrigues et al. A 1-Ma record of sea surface temperature and extreme cooling events in the North Atlantic: a perspective from the Iberian Margin. Quat. Sci. Rev. 172, 118-130 (2017). 
Acknowledgments:

Funding: We acknowledge financial support from Australian Research Council Discovery Project grants 0664621 (to JW), 110102185 (to RD, JW, JH, EW, AF and SF) and 160102969 (to RD, JW, GZ, EW and PF). We thank the Gruppo Speleologico Lucchese and the Federazione Speleologica Toscana for logistic and funding support. The SUERC contribution to this study falls within the framework of the Scottish Alliance for Geoscience, Environment and Society (SAGES). PB was the recipient of a University of Melbourne International Postgraduate Research Scholarship and Postgraduate Writing-Up Award supported by the Albert Shimmins Fund. JH was the recipient of an Australian Research Council Future Fellowship (FT130100801). PF acknowledges support from the EU through a Marie-Curie Reintegration grant (PERG-GA-2010-272134 - MILLEVARIABILI). DH acknowledges support from the UK Natural Environmental Research Council. EW is supported by a Royal Society Professorship. AHLV and TR received financial support from Fundação para a Ciência e a Tecnologia (FCT, Portugal) projects MOWCADYN (PTDC/MAR-PRO/3761/2012), WarmWorld (29897-02/SAICT/2017) and CCMAR (UID/Multi/04326/2013). Samples from the marine sites were provided by the Integrated Ocean Drilling Program to DH and AHLV.

Author contributions: RD, JW, JH, GZ and PB initiated the study. $\mathrm{PB}$ and JW performed U-Pb analyses; $\mathrm{PB}$ and $\mathrm{JH}$ the ${ }^{234} \mathrm{U} /{ }^{238} \mathrm{U}$ analyses; $\mathrm{PB}, \mathrm{JH}$ and $\mathrm{JT}$ the age-depth modelling; $\mathrm{PB}, \mathrm{RD}, \mathrm{CS}$ and AEF the stable isotope measurements. DH, AHLV and TR provided the marine core data. PB and RD performed the speleothem-ocean synchronization, which was scrutinised by DH, AHLV, TR, PF and EW. RD performed the analysis of the termination data for TI to TVII. SF provided the petrographic interpretations. All the authors contributed to the interpretation of the results. RD and PB wrote the manuscript, with all authors contributing to reviewing and editing.

Competing interests: All authors declare no competing interests. 
301 Data and materials availability: All data produced and used in this study is available from the 302 NOAA Paleoclimatology Data online repository at https://www.ncdc.noaa.gov/data-

303 access/paleoclimatology-data/datasets. The computer code for the finite growth rate depth-age model 304 is available upon request from John Hellstrom (j.hellstrom@unimelb.edu.au) and will be published 305 in full in a future publication.

306

307 Supplementary Materials:

308 Materials and Methods

309 References (32 - 67)

310 Figures S1-S8

311 Tables S1-S4

312 


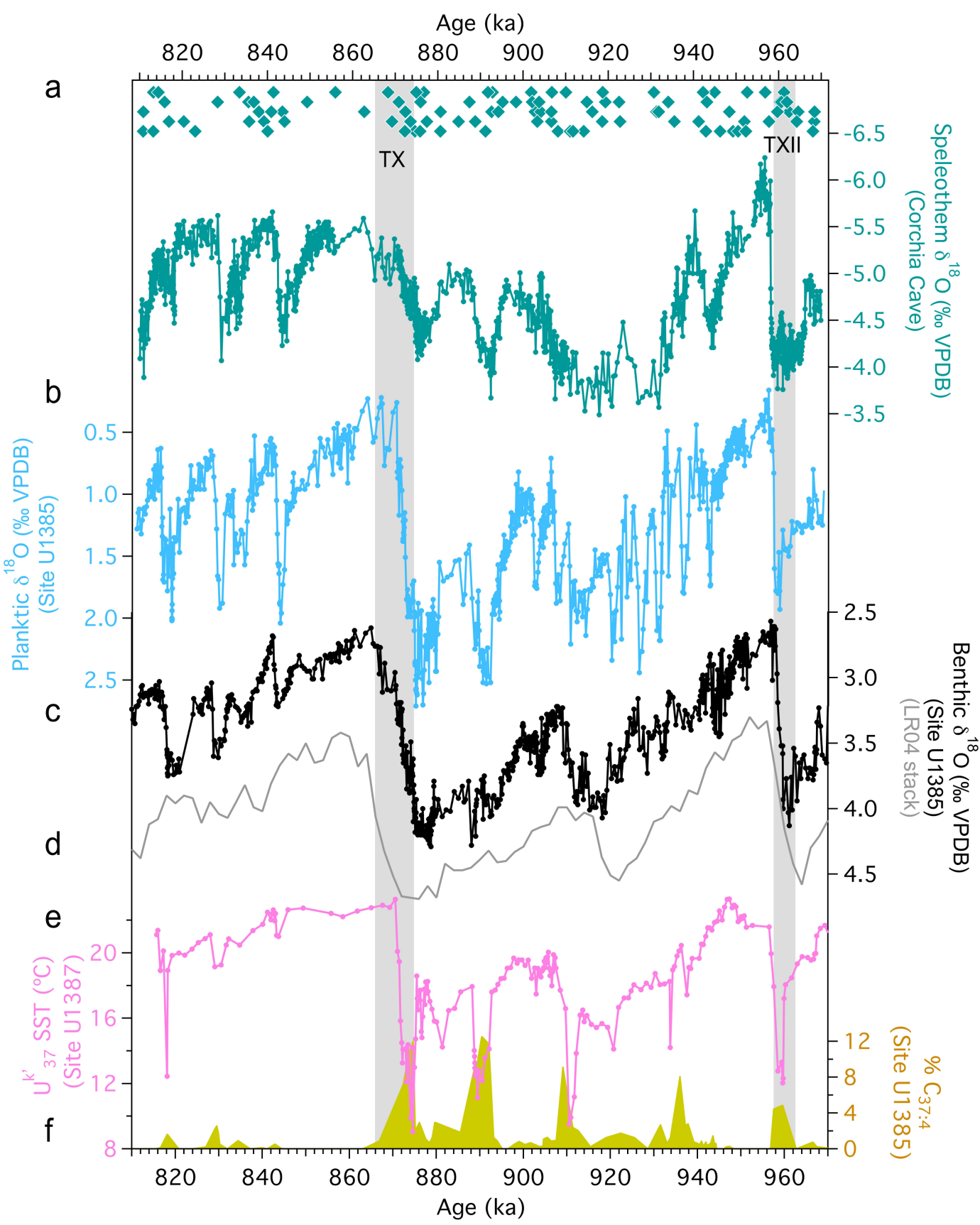

Fig. 1. North Atlantic ocean-core records from IODP Sites U1385 and U1387 for the period 970 to 810 ka tuned to the Corchia Cave speleothem $\delta^{\mathbf{1 8}} \mathrm{O}$ stack. (a) Corchia Cave speleothem $\delta^{18} \mathrm{O}$ stack with U-Pb ages shown (diamonds). (b, c) Planktic (blue, Globigerina bulloides) and benthic $\delta^{18} \mathrm{O}$ (black, Cibicidoides wuellerstorfi) from Site U1385. (d) The LR04 benthic $\delta^{18} \mathrm{O}$ stack (grey) of global ice-volume and deep-water temperature changes (4). (e) Alkenone $\mathrm{U}^{\mathrm{k}}{ }_{37}$ seasurface temperatures from Site U1387. (f) Per cent concentration of the $\mathrm{C}_{37: 4}$ alkenone from Site U1385 (31). The time series from Sites U1385 and U1387 are plotted on the Corchia Cave speleothem U-Pb chronology (Table S1 and fig. S1S4) using the tuning procedure outlined in the Methods and graphically presented in fig. S4b and S5. The LR04 stack is plotted on its original published age model (4). The two vertical grey bars highlight the position of Terminations X (TX) and XII (TXII). 

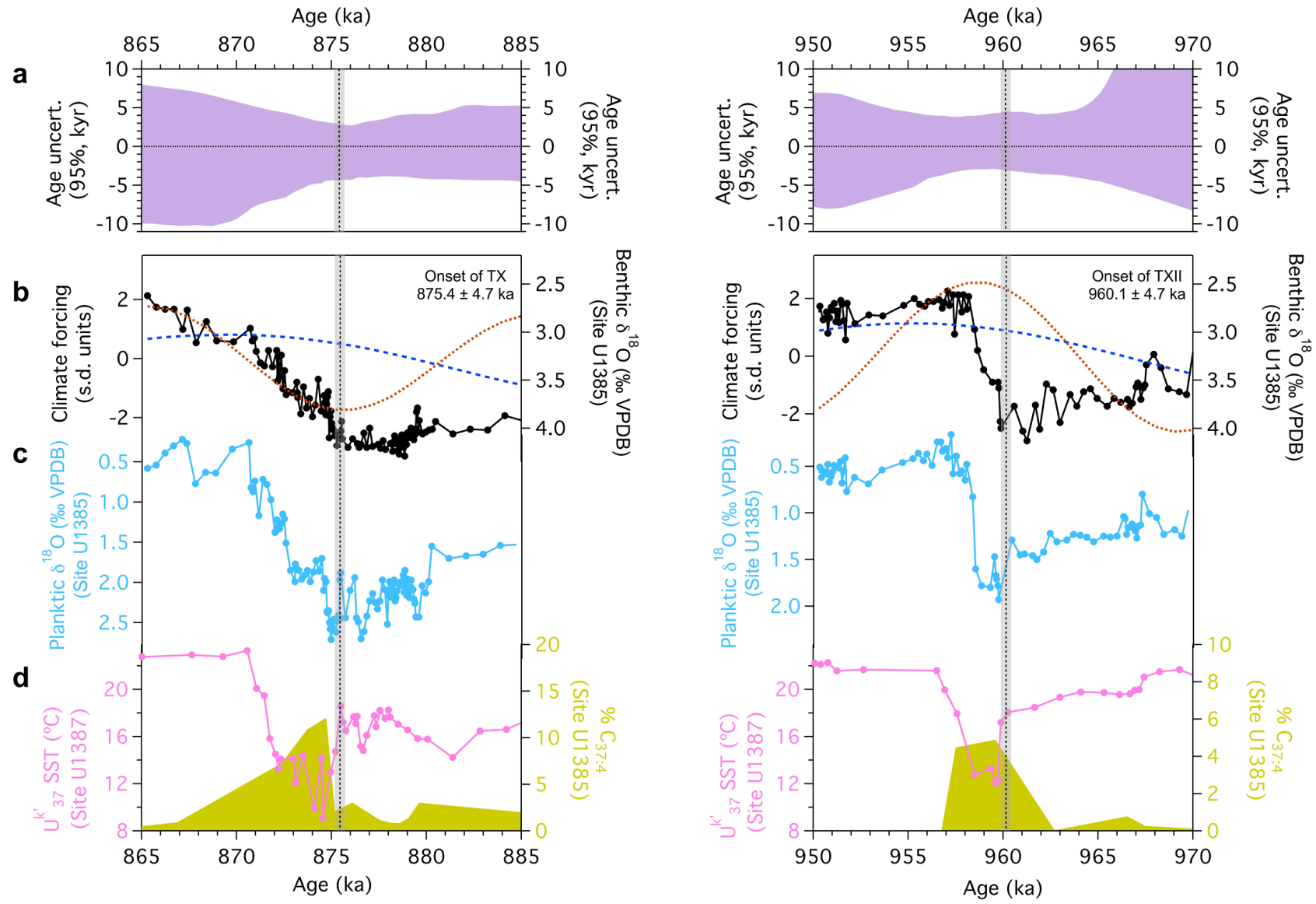

Fig. 2. Detail of ocean changes through Terminations X (left) and XII (right). (a) Time series of variations in age uncertainty for the Corchia Cave U-Pb chronology underpinning the ocean records from IODP Sites U1385 and U1387. (b, c) Benthic (Cibicidoides wuellerstorfi) and planktic $\delta^{18} \mathrm{O}$ (Globigerina bulloides) representing deep-ocean and surface-ocean temperature and sea-water $\delta^{18} \mathrm{O}$ changes at IODP Site U1385. Obliquity (blue dashed) and the inverse of precession (brown dotted) are also shown (1), both expressed in standard deviation (s.d.) units. (d) Alkenone $\mathrm{U}^{\mathrm{k}}{ }_{37}$ sea-surface temperatures from IODP Site U1387 and per cent concentration of the $\mathrm{C}_{37: 4}$ alkenone from Site U1385 (31), a proxy for freshwater incursions at the coring site. The grey vertical bars mark the position of the commencement of each termination. Termination ages are shown; the \pm value incorporates uncertainties from (22). 
a

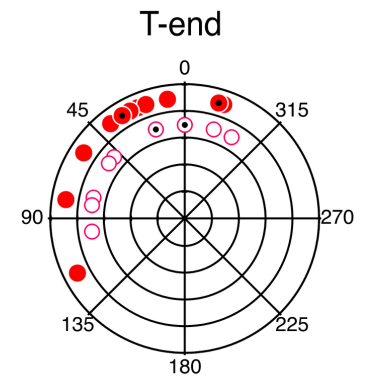

T-mid

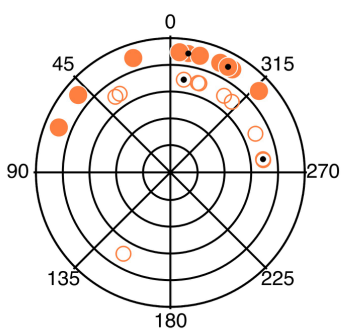

T-start

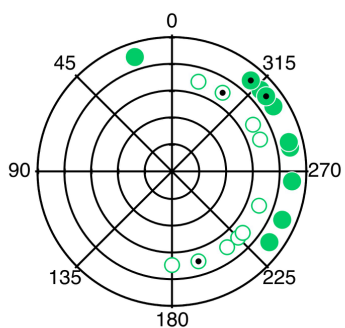

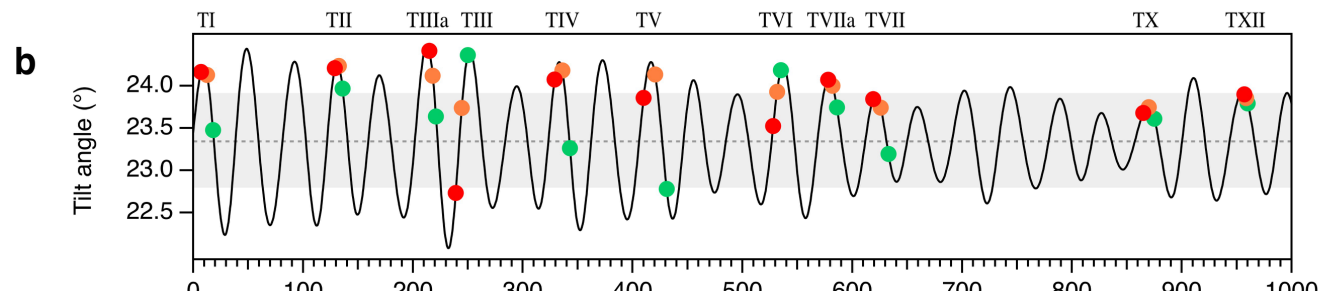

c

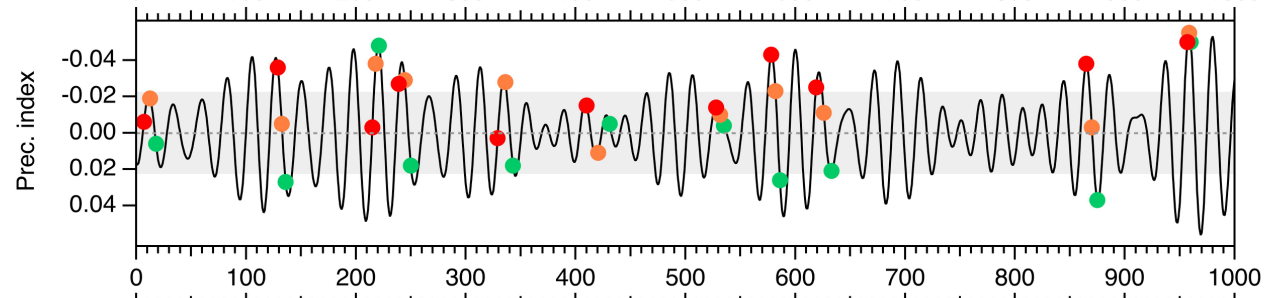

d
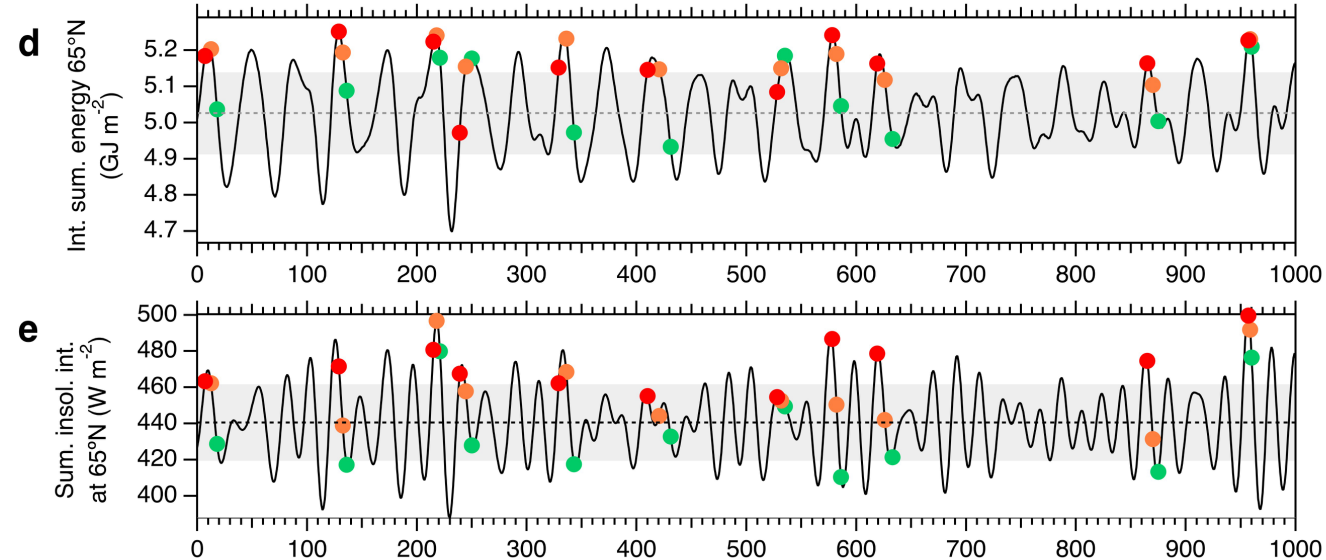

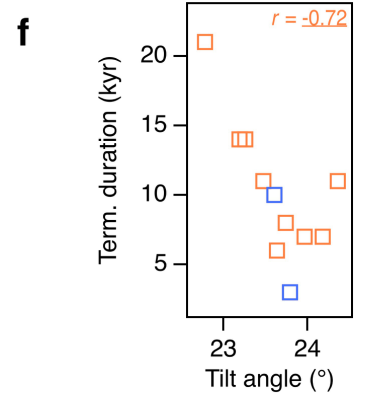

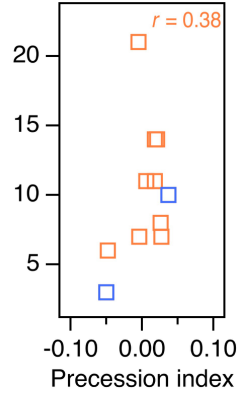

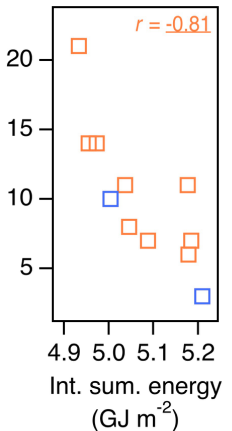

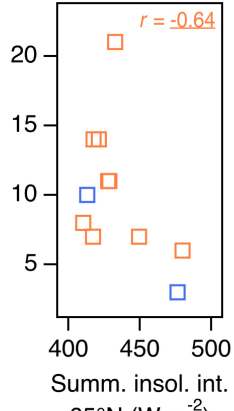
$65^{\circ} \mathrm{N}\left(\mathrm{W} \mathrm{m}^{-2}\right)$

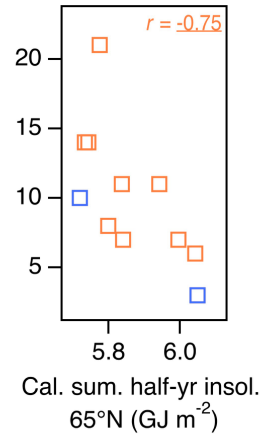


339 Fig. 3. Radiometric-based timing and duration of 11 terminations (TI - TVII, TX, TXII) compared to astronomical 340 and insolation parameters. (a) Polar plots showing phasing in degrees for both obliquity (solid circles) and precession 341 (open circles) at the start, (green), midpoint (orange) and end (red) of each termination. The black symbols in each series 342 highlight the phasings for TX and TXII. (b-e) Phasing between the timing of the start (green), midpoint (orange) and end 343 (red) of each termination and (b) obliquity (1), (c) precession (1), (d) integrated summer energy $\left(>275 \mathrm{~W} / \mathrm{m}^{2}\right)$ at $65^{\circ} \mathrm{N}(17)$, 344 and (e) insolation intensity for July at $65^{\circ} \mathrm{N}$ (1). (f) Scatterplots and Pearson $r$ correlation coefficients for the duration of 34511 terminations (18; Tables S3 and S4) versus orbital and insolation metrics at the start of each termination (left to right: 346 obliquity (1), precession index (1), integrated summer energy $\left(>275 \mathrm{~W} / \mathrm{m}^{2}\right)$ at $65^{\circ} \mathrm{N}(13)$, July insolation intensity at $65^{\circ} \mathrm{N}$ 347 (1) and caloric summer half-year energy at $\left.65^{\circ} \mathrm{N}(9)\right)$. The blue symbols highlight the data for TX and TXII. Underlined $r$ 348 values are statistically significant $(p<0.05 ; d f=9)$. 

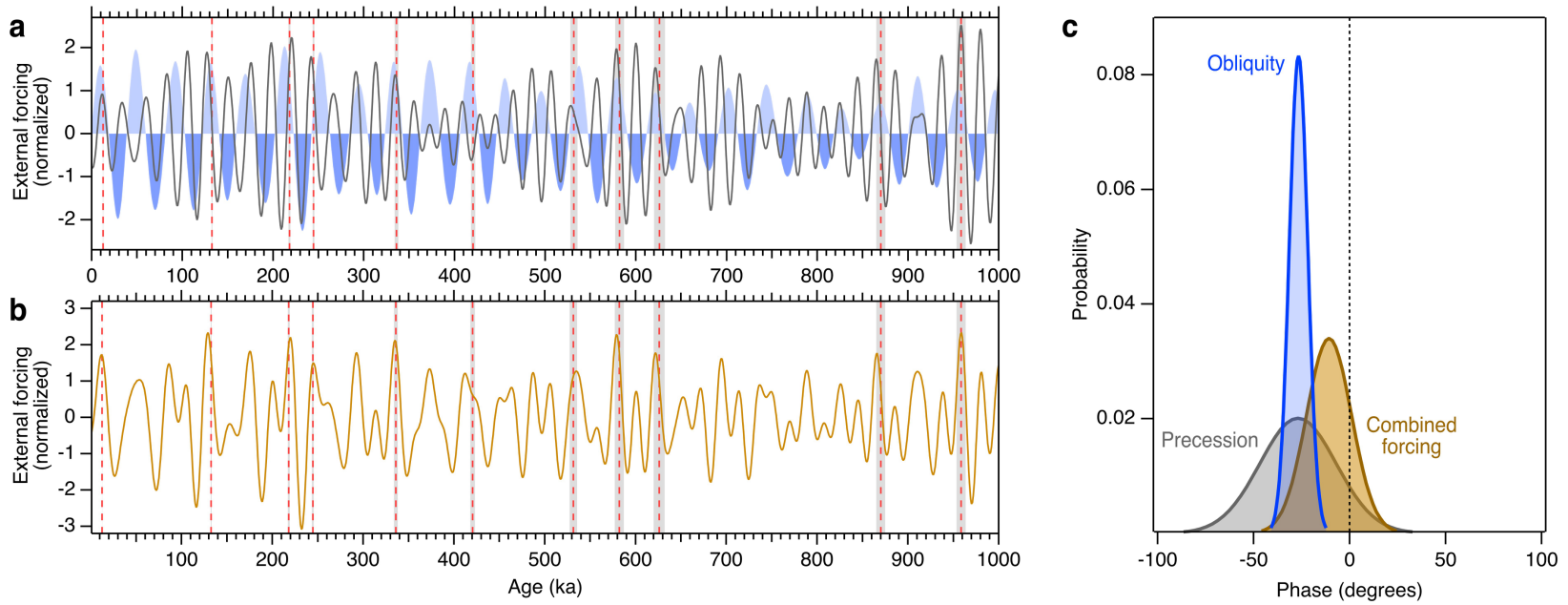

Fig. 4. Comparison between the timing of 11 termination midpoints and normalized orbital and insolation metrics.

(a) Termination timing (red-dashed vertical lines) versus obliquity (ref. 1; light and dark blue shaded) and precession index (ref. 1; dark grey, shown inverted). Gray vertical shadings are the 95\% uncertainties of the midpoint age estimates, which for the younger terminations (18) are small compared to the line thickness. (b) Termination timing as for (a) versus an insolation forcing metric that combines both obliquity and precession variability $(13,18)$.

(c) Phase probability distributions for precession, obliquity and the combined precession-obliquity insolation forcing metric of ref. 13 (18). Each distribution is an error-weighted phase mean and uncertainty based on the phase and uncertainty of 11 individual terminations at their midpoint age (fig. S8). Individual phase uncertainties were derived using the $95 \%$ uncertainties of the midpoint ages (18). The vertical zero line represents the phase maximum for each parameter. A negative phase represents termination ages that precede the maximum phase of the orbital parameter. The distribution for precession is inverted so 


\section{Science \\ DIAAAS}

\section{Supplementary Materials for}

\section{Persistent influence of obliquity on ice-age terminations since the Middle Pleistocene Transition}

Petra Bajo ${ }^{1,2,3}$, Russell N. Drysdale ${ }^{1,4 *}$, Jon D. Woodhead ${ }^{5}$, John C. Hellstrom ${ }^{5}$, David Hodell ${ }^{6}$, Patrizia Ferretti ${ }^{7,8}$, Antje H.L. Voelker ${ }^{9,10}$, Giovanni Zanchetta ${ }^{11}$, Teresa Rodrigues ${ }^{9,10}$, Eric Wolff ${ }^{6}$, Jonathan Tyler ${ }^{12}$, Silvia Frisia ${ }^{13}$, Christoph Spöt $1^{14}$, Anthony E. Fallick ${ }^{15}$

Correspondence to: $\underline{\text { nd@ } @ \text { unimelb.edu.au }}$

\section{This PDF file includes:}

Materials and Methods

References (32 to 66)

Figs. S1 to S7

Tables S1 to S4

\section{Affiliations:}

${ }^{1}$ School of Geography, University of Melbourne, Carlton, Victoria 3053, Australia.

${ }^{2}$ Australian Nuclear Science and Technology Organisation, Lucas Heights, NSW 2234, Australia.

${ }^{3}$ Croatian Geological Survey, Milana Sachsa 2, Zagreb, Croatia

${ }^{4}$ Laboratoire EDYTEM - UMR5204, Université de Savoie Mont Blanc, 73376 Le Bourget du Lac, France.

${ }^{5}$ School of Earth Sciences, University of Melbourne, Parkville, Victoria 3010, Australia.

${ }^{6}$ Department of Earth Sciences, University of Cambridge, Cambridge CB2 3EQ, UK.

${ }^{7}$ Istituto per la Dinamica dei Processi Ambientali, Consiglio Nazionale delle Ricerche (IDPA-CNR), Venice 30172, Italy.

${ }^{8}$ Dipartimento di Scienze Ambientali, Informatica e Statistica, Università Ca' Foscari, Venice 30172, Italy

${ }^{9}$ Instituto Português do Mar e da Atmosfera (IPMA), Divisão de Geologia e Georecursos Marinhos, 1495-006 Lisbon, Portugal.

${ }^{10}$ Centre of Marine Sciences (CCMAR), University of the Algarve, 8005-139 Faro, Portugal

${ }^{111}$ Department of Earth Sciences, University of Pisa, Pisa 56100, Italy.

${ }^{12}$ Department of Earth Sciences, University of Adelaide, North Terrace, South Australia, 5005, Australia

${ }^{13}$ School of Environmental and Life Sciences, University of Newcastle, Callaghan 2308, NSW, Australia.

${ }^{14}$ Institute of Geology, University of Innsbruck, 6020 Innsbruck, Austria.

${ }^{15}$ Scottish Universities Environmental Research Centre, East Kilbride G75 0QF, Scotland, UK.

*Corresponding author: rnd@unimelb.edu.au 


\section{Materials and Methods}

\section{$\underline{\text { 1. Corchia Cave speleothem sampling and stable isotope analyses }}$}

Four stalagmites $(\mathrm{CC} 8, \mathrm{CC} 30, \mathrm{CC} 119$ and $\mathrm{CC} 122)$ were collected as broken pieces from Galleria delle Stalattiti, a chamber located $\sim 1 \mathrm{~km}$ from the tourist entrance of Corchia Cave, Italy $\left(44^{\circ} 01^{\prime} 50^{\prime \prime} \mathrm{N}, 10^{\circ} 17^{\prime} 50^{\prime \prime} \mathrm{E}\right)$. Details of the site and chamber characteristics are provided elsewhere $(19,32,33)$. The stalagmites were halved along their vertical growth axis, polished, and then mounted in resin to prevent breaks during subsequent sampling. In section, the stalagmites are white to grey in color and composed of compact translucent to opaque primary calcite devoid of microscopic evidence of either early or late diagenetic alteration. A core sample drilled from a fifth speleothem (CD3), an actively forming subaqueous calcite mound growing in a pool within the same cave gallery $(33,34)$, was also used in this study.

Stable-isotope analyses for each stalagmite were initially conducted at low resolution on powder samples drilled at 1-mm increments along each specimen's growth axis using a tungsten-carbide dental-drill bit attached to either a Taig CNC micromilling lathe or a Dremel hand drill. Through the portions corresponding to TXII and TX in CC8, micromilling was undertaken at a higher resolution $(250 \mu \mathrm{m})$ to improve detail. Most of the stable isotope analyses were conducted at the Scottish Universities Environmental Research Centre (East Kilbride, UK), The University of Newcastle (Australia) and The University of Melbourne (Australia) on the same model (AP2003/GV2003) mass spectrometer, each operated in continuous-flow mode. The results are expressed in delta notation relative to the VPDB standard. Long-term analytical precision of in-house reference materials of Carrara marble, previously calibrated to international reference materials NBS-18 and NBS-19, was better than 0.05 and $0.1 \%$ o $(1 \sigma)$ for $\delta^{13} \mathrm{C}$ and $\delta^{18} \mathrm{O}$ respectively (23). Analyses were repeated where $\delta^{18} \mathrm{O}$ differed by more than $0.4 \%$ between adjacent samples. The CD3 core section was microsampled at $200-\mu \mathrm{m}$ increments using a New Wave Micromill and analysed by continuous-flow IRMS at the Institute of Geology, University of Innsbruck, using a Thermo Fisher Delta ${ }^{\text {plus }} \mathrm{XL}$ (35), on which the long-term analytical uncertainty for $\delta^{18} \mathrm{O}$ and $\delta^{13} \mathrm{C}$ is $0.08 \%$ and $0.06 \%$ respectively (36).

\section{$\underline{\text { 2. Corchia Cave speleothem geochronology }}$}

Samples for $\mathrm{U}-\mathrm{Pb}$ dating were extracted at the University of Melbourne using a dental air drill fixed to a manually navigated milling machine. Despite the high $\mathrm{U}$ and low common $\mathrm{Pb}$ content of these samples (Table $\mathrm{S} 1$ ), their relatively young age required the use of subsamples between 50 and $100 \mathrm{mg}$ to allow for accurate measurement of the radiogenic $\mathrm{Pb}$ component. Subsamples were individually immersed briefly in $\sim 0.1 \mathrm{M} \mathrm{HCl}$ in order to remove potential surface contamination from drilling then thoroughly washed in ultrapure water. All subsequent operations were performed in a multiple-HEPA filtered clean air laboratory. The dried samples were weighed out, dissolved in $6 \mathrm{M} \mathrm{HCl}$ and spiked with a mixed ${ }^{233} \mathrm{U} /{ }^{205} \mathrm{~Pb}$ tracer solution. Sample-spike equilibration was ensured by overnight heating on a hotplate followed 
by complete drying down. $\mathrm{U}$ and $\mathrm{Pb}$ were chemically separated following the ion-exchange procedure (20) and isotopic ratios measured on a $\mathrm{Nu}$ Instruments Plasma multi-collector-inductively coupled plasma mass spectrometer (MC-ICPMS) at The University of Melbourne. The NIST SRM981 reference material for $\mathrm{Pb}$ and an internal ${ }^{238} \mathrm{U} /{ }^{235} \mathrm{U}$ ratio of 137.88 for $\mathrm{U}$ were used for mass-fractionation corrections, employing software developed in-house for this purpose. Blank corrections for $\mathrm{Pb}(10 \pm 5 \mathrm{pg})$, together with isotope-dilution calculations, were performed using the algorithm published in ref. 37. U blanks were negligible. Further details on the U-Pb data treatment can be found in ref. 20-22.

The majority of previous $\mathrm{U}-\mathrm{Pb}$ dating studies of speleothems have used isochron approaches to calculate sample ages (e.g. 20, 21, 37, 38). Although such an approach is undoubtedly the most robust, it is difficult to employ when attempting high-resolution chronologies because it uses large amounts of sample and is very time intensive. Following successful determination of 20 isochrons on the studied speleothems, we instead adopted a single-aliquot approach to increase the resolution of the age model. This methodology has been discussed elsewhere $(21,22)$ but, in brief, where common $\mathrm{Pb}$ compositions either in one speleothem or in the same cave site are well constrained, and when the speleothems are relatively radiogenic, the mean estimate of common $\mathrm{Pb}$ based on previously determined isochron data, and its uncertainty, can be used in the calculation of model ages based upon single-aliquot analyses (22). The U-Pb dating of CC8 was the first documented example of using this method (22). This approach has since been updated, taking into account an improved estimate of the common- $\mathrm{Pb}$ composition for these stalagmites by addition to the previous dataset of one new isochron for CC8 and 13 isochrons for stalagmites CC119 and CC122 (fig. S1). Data from these new isochrons refined the previously published common $\mathrm{Pb}$ estimate from $0.818+0.006 /-0.011$ to $0.81341+/-0.00483$ (fig. $\mathrm{S} 2$ ), although we stress that the new mean value is within the previously estimated $95 \%$ uncertainty.

In general, isochrons for stalagmites CC122 and CC119 have a better fit (i.e. a lower MSWD) than the previously published CC8 isochrons (22) (fig. S1). This is the result of a larger spread in isotopic ratios for these samples as well as their higher $\mathrm{Pb}$ content, which enabled improved precision in isotopic measurements for individual aliquots. However, as demonstrated in ref. 21, application of a single-aliquot approach to relatively unradiogenic samples results in less accurate and precise ages. For this reason, we employed a filter and rejected from the age-depth modeling all samples with ${ }^{238} \mathrm{U} / 206 \mathrm{~Pb}$ ratios lower than 2500 . The rejected samples are marked with superscript $\mathrm{R}$ in Table S1. However, we stress that their inclusion in the age-depth modeling would affect neither the mean model age nor its uncertainty due to their large age uncertainties, which are, in almost all cases, $>25$ kyr. Three additional samples (fig. S2) were identified as outliers and also excluded from the age-depth modeling.

Since speleothems are often deposited out of secular isotopic equilibrium with respect to initial ${ }^{234} \mathrm{U} /{ }^{238} \mathrm{U}$ activity (39), thus necessitating a disequilibrium correction, we chemically prepared and measured ${ }^{234} \mathrm{U} /{ }^{238} \mathrm{U}$ isotope ratios on an aliquot of each sample separately (40). The analyses were performed on the Nu Instruments Plasma MC-ICPMS at The University of Melbourne. Uranium isotopic reference materials NBL-112A and HU-1 were used to correct for external 
${ }^{234} \mathrm{U}{ }^{238} \mathrm{U}$ variability. Disequilibrium-corrected $\mathrm{U}-\mathrm{Pb}$ ages and their uncertainties were calculated using an in-house macro (22). All isotope ratios and the final ages corrected for initial disequilibrium effects are provided in Table S1.

\section{Compilation of the Corchia Cave speleothem stack}

We developed a composite isotope series following the procedure used to produce a Corchia Cave $\delta^{18} \mathrm{O}$ stack for the Last Interglacial (23). We first synchronised the CD3, CC30, CC119 and CC122 records to the depth scale of CC8 (fig. S4a), which has the longest record of the four dated stalagmites. The cross-tuning was based on pattern-matching both $\delta^{18} \mathrm{O}$ and $\delta^{13} \mathrm{C}$ profiles. The offsets between the stalagmite and $\mathrm{CD} 3 \delta^{13} \mathrm{C}$ profiles are not surprising: percolation waters feeding each stalagmite pass through a unique fracture system causing different hydrogeochemical evolution pathways, whereas CD3 records the response to the 'population' of drips entering a large pool.

Stalagmite CC 8 contains two hiatuses, at $337 \mathrm{~mm}$ and $355.5 \mathrm{~mm}$ depth. These are convincingly spanned by $\mathrm{CC} 30$ (the younger hiatus) and CD3 (both hiatuses); there is good agreement among the speleothems in the $\delta^{18} \mathrm{O}$ and $\delta^{13} \mathrm{C}$ profiles either side of each hiatus. We then developed a 'synthetic' stack depth scale that takes into account the need to add depth segments through both hiatuses of $\mathrm{CC} 8$, as well as to accommodate the growth of $\mathrm{CC} 122$ beyond the base of CC8 (i.e. below $\sim 824 \mathrm{~mm}$ ). For the older CC8 hiatus, the spacing between the five isotope data points of CD3 that span this hiatus was increased to account for the $\sim 13 \mathrm{x}$ faster growth rate of CC 8 compared to CD3 over the whole period of overlap for the two speleothems. For the younger hiatus, the spacing of the 13 isotope data points of CC 30 that span this hiatus was decreased to account for the $\sim 3 \mathrm{x}$ faster growth rate of $\mathrm{CC} 30$ compared to $\mathrm{CC} 8$ over the whole period of overlap for these two speleothems. Since the CC8 record between the two hiatuses (corresponding to 337.0 to $377.1 \mathrm{~mm}$ from the top of composite depth scale) is of very low resolution, we inserted the higher resolution CC30 and CD3 stable isotope data. Finally, for the base of $\mathrm{CC} 122$, which covers the oldest part of the stacked record, the spacing of each sampling point was reduced to $0.5 \mathrm{~mm}$, compared to the original $1 \mathrm{~mm}$. This accounts for the $\sim 2 \mathrm{x}$ faster growth rate of CC122 compared to CC8 over their entire period of overlap. The final stacked series are shown as the grey curves in fig. S3a.

Further support for the match between the stalagmites comes from their individual age-depth models: the agedepth model for each of CC30, CC119 and CC122 overlaps within its respective uncertainties with that of CC8 (fig. S4a).

To place the composite stable isotope series onto an age scale, an age-depth model (ADM) was developed through the entire population of U-Pb ages on the abovementioned stack depth scale using a Monte-Carlo-based Finite Positive Growth Rate Model (41-43) (fig. S3b). Input parameters in this ADM approach are sample age and depth for each age determination together with their uncertainties. For each iteration of the model, age and depth for each sample are randomised according to their uncertainties, then sorted by their randomised depths and a least-squares procedure used to find the sequence of connecting positive growth rate age-depth line segments which best fit the uncertaintyweighted age-depth data. For each iteration, the algorithm also attempts to minimise the sum of the squares of relative 
growth rate change between adjoining age-depth line segments, subject to a user-controlled weighting factor that balances the importance of this against maximizing model fit to the measured ages (41). Where this weighting is too far in favour of a strict fit to age data, the resulting ADM can exhibit implausibly high swings of growth rate between adjacent samples; if too far in favour of minimizing growth rate change, the resulting ADM can appear insufficiently fitted to the age data. An acceptable range of growth-rate-minimization weighting factors was determined visually for the age-depth model after which that factor was randomized within this range for each of the 10,000 iterations of the Monte-Carlo ADM determination. The 3rd-, 50th- and 97th-percentile interpolated ages were determined at 500 evenly spaced steps along the stack depth scale and interpolated to give age and its uncertainty at any depth $(41,43)$ (fig. S3c). A review of diverse speleothem age-depth modelling procedures, including a version of the algorithm used here, found minor differences for sparsely-spaced age determinations but concluded that differences between model approaches were not significant for densely spaced age data (relative to uncertainty) (42), as is the case for this study. Similarly, the use of the growth-rateminimisation weighting factor, which can have significant effect on the form of ADMs for sparse age data, has little influence in this case. This is confirmed by good correlation between our age-depth modelling output and another ADM approach (Bacon) described later in the text.

Where the age uncertainties of many individual age determinations overlap in time, ADM uncertainty (determined using any ADM technique) can be considerably smaller than that of individual ages (similarly to the calculation of a weighted mean of repeat age determinations of a single age horizon where uncertainly of the mean age is reduced by approximately the square root of the number of repeat measurements). This reduction of uncertainty is only valid where individual ages have independent, uncorrelated uncertainties, i.e. where there is no common source of uncertainty. Following ref. 22, we have assumed that the initial ${ }^{207} \mathrm{~Pb} /{ }^{206} \mathrm{~Pb}$ ratio uncertainty determined on the basis of isochron determinations (fig. S2) is composed of equal components of correlated (i.e. common to all samples, arising from imprecision in the determination of mean initial value) and uncorrelated (i.e. due to natural variability between age measured samples). Three ADMs were calculated using ages calculated with the median, upper and lower bounds of the correlated initial ${ }^{207} \mathrm{~Pb} /{ }^{206} \mathrm{~Pb}$ and the difference between their median $\mathrm{ADM}$ curves used to determine the correlated component of age uncertainty, which was then added to the uncertainty envelope derived using uncorrelated initial ${ }^{207} \mathrm{~Pb} /{ }^{206} \mathrm{~Pb}$ variability about its mean value. This approach is described in greater detail in ref. 22 with the difference that, here, isochron ages are used alongside single-aliquot ages in the ADM where available instead of choosing the most radiogenic single-aliquot age from each individual isochron set. This modification was introduced to acknowledge that the results based on the isochron method are more robust as they do not rely on globally estimated common $\mathrm{Pb}$ composition and are free of significant correlated uncertainty. Corchia Cave speleothems are amongst the leastcontaminated by detrital thorium ever reported, with ${ }^{230} \mathrm{Th} /{ }^{232} \mathrm{Th}$ activity ratios of over 100,000 measured in each of the 
three stalagmites studied here, substantially in excess of the suggested minimum value of 1000 at which U-Th age corrections can typically be considered insignificant (44).

\section{Foraminifer stable isotope and alkenone SST analyses}

Data from two ocean-sediment cores were used in this study. From Integrated Ocean Drilling Program (IODP) Site U1385 $\left(36.8^{\circ} \mathrm{N}, 7.7^{\circ} \mathrm{W}\right)(30)$, we assembled new, high-resolution planktic and benthic foraminifer $\delta^{18} \mathrm{O}$ series to complement the published $\% \mathrm{C}_{37: 4}$ data; the published SST series from this Site (31) are insufficiently resolved for comparing with the high-resolution foraminifer $\delta^{18} \mathrm{O}$ data, so we assembled a new $\mathrm{U}^{\mathrm{k}}{ }_{37}$ biomarker-based SST and planktic $\delta^{18} \mathrm{O}$ series from IODP Site U1387 (45) $\left(36.5^{\circ} \mathrm{N}, 7.43^{\circ} \mathrm{W}\right)$. The surface-water composition of both sites is similar on account of their close proximity (46), enabling the two ocean-core records to be synchronized (fig. S5).

The new planktic and benthic $\delta^{18} \mathrm{O}$ series from Site U1385 presented here expand the previously published lowresolution data (30). The core was sampled along the spliced composite section at a constant sample spacing of $2 \mathrm{~cm}$. Stable isotopes were measured on the planktic foraminifer Globigerina bulloides selected from the 250 - to $355-\mu \mathrm{m}$ size fraction and the benthic foraminifer Cibicidoides wuellerstorf $i$ from the $>212-\mu \mathrm{m}$ fraction. Foraminifer tests were cleaned prior to analysis (30) and isotopic analyses performed using a VG SIRA mass spectrometer with a Multicarb system for samples with a mass exceeding $80 \mu \mathrm{g}$. Analytical precision $(1 \sigma)$ is estimated to be $\pm 0.08 \%$ for both $\delta^{18} \mathrm{O}$ and $\delta^{13} \mathrm{C}$. For smaller samples $(<80 \mu \mathrm{g})$, measurements were performed on a Thermo Finnigan MAT253 mass spectrometer fitted with a Kiel device. Analytical precision $(1 \sigma)$ is estimated to be $\pm 0.08 \%$ for $\delta^{18} \mathrm{O}$ and $\pm 0.06 \%$ for $\delta^{13} \mathrm{C}$, respectively. Results are reported relative to V-PDB. All isotope measurements were made in the Godwin Laboratory, University of Cambridge.

For Site U1387, the alkenone-derived SST and planktic $\delta^{18} \mathrm{O}$ series were reconstructed from cores U1387A-22X to U1387A-25X and U1387B-21X to U1387B-24X (47). Sample spacing was adjusted to avoid coring disturbances (biscuiting) but yields an average resolution of 12-13 cm (approximately $390 \mathrm{yr}$ ) for the planktic $\delta^{18} \mathrm{O}$ record and $24-26$ $\mathrm{cm}(780 \mathrm{yr})$ for the SST record. The resolution of both records was increased to an average of $6 \mathrm{~cm}$ during the MIS $22-$ 21 transition (TX). Stable-isotope analyses were conducted on the foraminifer Globigerina bulloides on between 8 and 15 specimens collected from the $>250-\mu \mathrm{m}$ fraction (46). The samples were measured on either a Finnigan MAT 251 or 252 mass spectrometer coupled to an automated Kiel I carbonate preparation system, at MARUM (University Bremen, Germany). The long-term precision $(1 \sigma)$ is $\pm 0.05 \%$ for $\delta^{13} \mathrm{C}$ and $\pm 0.07 \%$ for $\delta^{18} \mathrm{O}$ based on repeated analyses of internal (Solnhofen limestone) and external (NBS-19) carbonate standards.

For the U1387 SST reconstruction $(31,45,48)$, the molecular lipids (including alkenones) were extracted from the freeze-dried, ground sediment samples by sonication using dichloromethane. After hydrolyzation with $6 \%$ potassium 
hydroxide in methanol to eliminate interferences from wax esters, the neutral lipids were then extracted with hexane, evaporated to dryness under a nitrogen gas stream then finally derivatised with bis(trimethylsilyl)trifluoro-acetamide. The lipids were analyzed on the DivGM's Varian Gas chromatograph Model 3800 equipped with a septum programmable injector and a flame ionization detector $(31,49)$. Annual mean SST was calculated from the alkenone unsaturation index $\mathrm{U}^{\mathrm{k}^{\prime}} 37$ (50) using the equation from ref. 51.

\section{Synchronization of the U1385 and U1387 ocean records to the Corchia Cave speleothem time scale} The data from Site U1385 were anchored to the Corchia Cave chronology by synchronizing the planktic $\delta^{18} \mathrm{O}$ to the speleothem $\delta^{18} \mathrm{O}$. The rationale for this approach is as follows. Previous studies on Corchia speleothems (19, 26, 52) argued that millennial-to-orbital-scale changes in the speleothem $\delta^{18} \mathrm{O}$ are responsive to variations in SST in the North Atlantic and western Mediterranean Sea. Under this scenario, a warmer SST results in greater moisture advection from the North Atlantic to the cave site, increasing the quantity of rainfall and lowering the rainfall (and speleothem) $\delta^{18} \mathrm{O}$ via the 'amount effect' (53). The converse occurs during periods of SST cooling. The dominance of the amount effect is reinforced by the local topography at the cave site, where the mountains rise to almost $2000 \mathrm{~m}$ above the nearby coastal plain and constitute an imposing orographic barrier. However, it has been argued that during a termination Corchia speleothem $\delta^{18} \mathrm{O}$ can be affected by meltwater released from decaying continental ice-sheets around the North Atlantic margin (27). Regional planktic $\delta^{18} \mathrm{O}$ is a function of the temperature of (bio)mineralization and the $\delta^{18} \mathrm{O}$ composition of the source waters, and except during periods of large-scale meltwater flux, source-water changes are minimal, causing the planktic $\delta^{18} \mathrm{O}$ to closely track SST (28). However, meltwater pulses during terminations cause a lowering of surface ocean $\delta^{18} \mathrm{O}$ that more than counters the effect of reduced ocean temperature on planktic $\delta^{18} \mathrm{O}$, causing a decoupling between the planktic $\delta^{18} \mathrm{O}$ and SST $(27,29)$. This is seen vividly during the well-studied TII interval, where SST, the tetraunsaturated alkenone $\mathrm{C}_{37: 4}$, and the planktic $\delta^{18} \mathrm{O}$ show the combined and unequivocal effects of cooling and freshening of the surface ocean as ice-sheet meltwaters penetrated southwards to the Iberian margin and entered the western Mediterranean Sea $(27,29)$. As the predominant sources of water vapour reaching Corchia Cave are of North Atlantic and western Mediterranean origin (19), the $\delta^{18} \mathrm{O}$ of air masses reaching Corchia would be directly influenced by large-scale, meltwater-driven changes in surface-ocean $\delta^{18} \mathrm{O}$, such as those that occur during a termination. This is supported in principle by a recent study using an isotope-enabled Earth system model, which shows a depletion in precipitation over Greenland and Brazil during meltwater events (54). Thus, the speleothem and planktic $\delta^{18} \mathrm{O}$ share a common set of drivers, making the planktic $\delta^{18} \mathrm{O}$ a more robust tuning target than SST, as previously argued (27). This is evident in the strong structural similarity between the speleothem and planktic $\delta^{18} \mathrm{O}$ series (Fig. 1 and fig. S4b), whereas the similarity between the speleothem $\delta^{18} \mathrm{O}$ and SST is somewhat lower, particularly at the sub-orbital scale. Nevertheless, 
assigning the SST series, rather than the planktic $\delta^{18} \mathrm{O}$ series, as the tuning target would make no age difference in the case of TXII and would lower the age estimate by not more than $2 \mathrm{kyr}$ in the case of TX.

To complete the synchronization procedure, the Site U1387 data were tuned to the depth scale of Site U1385 using their respective planktic $\delta^{18} \mathrm{O}$ series (fig. S6). The Corchia chronology for Site U1385 was then interpolated to the Site U1387 record, enabling the SST series from the latter to be placed onto the same time scale as the speleothem stack, and the $\mathrm{U} 1385$ planktic and benthic $\delta^{18} \mathrm{O}$ and $\mathrm{C}_{37: 4}$ alkenone series. The two synchronizations were implemented in AnalySeries (55) by selecting as chronostratigraphic markers a series of control points that define oscillations assumed to be common to both records (fig. S4b and S6).

The resulting age model for Site U1385 (herein referred to as 'CC-Raw') yielded sedimentation rates ranging between 0.02 and $0.85 \mathrm{~m} \mathrm{kyr}^{-1}$, which exceeds those determined from an earlier study that considered four alternative age models (Table S2) (30). Whilst an increase in the amplitude of sedimentation rates can be expected due to the higher density of control points used in our tuning, the final age model should still yield a plausible range of sedimentation rates. The largest source of error in the cave-ocean correlation that can lead to extreme sedimentation rates stems from the fact that only the ocean series is 'moved' during the tuning process, whereas the speleothem series remains fixed in time despite radiometric age uncertainties that, for the majority of the record, exceed $3 \mathrm{kyr}$ (fig. S3c). To account for this, the $\mathrm{U}-\mathrm{Pb}$ model ages and age uncertainties for each control point were combined with a Monte Carlo approach to derive two alternative age-depth models for Site U1385, with sedimentation rate employed as a constraint. The first was implemented using the software Bacon (56) in the statistical package R and is based on 91 x $0.2 \mathrm{~m}$ sequential sections of Site U1385, with the following parameter settings: a mean accumulation rate of $0.1 \mathrm{~m} \mathrm{kyr}^{-1}$; an accumulation shape of 1.5 ; a memory strength of 4; and a memory mean of 0.7 . A total of 50,000 Markov Chain Monte Carlo iterations were performed, producing the model shown in fig. S6 (herein called 'CC-Bacon'). The second simulation was conducted using the Finite Positive Growth Rate Model employed to generate the original Corchia speleothem age model shown in Fig. S3b (herein called 'CC-FGR'). Here, the model was adjusted to accommodate a mean sedimentation rate of $0.10 \mathrm{~m} \mathrm{kyr}^{-1}$ and allowing the sedimentation rate to vary by a factor of approximately three around this mean value, consistent with the earlier models (30). The output is shown in fig. S6, along with the derived sedimentation rate ranges, which are compared against the planktic $\delta^{18} \mathrm{O}$ on the CC-Raw time scale. The sedimentation rate statistics and termination ages for each model are summarised in Table S2.

The CC-Bacon and CC-FGR simulations produced U1385 age model ages that fall within the age-model envelope of the CC-Raw model output. The derived TX and TXII age estimates deviate by no more than $13 \%$ of the total age-error envelope of the CC-Raw model (i.e. they are well within $1 \sigma$ uncertainty). We therefore use the CC-Raw age model output to assign age estimates and uncertainties for TX and TXII (Fig. 2; Table S2). 
The CC-Bacon and CC-FGR sedimentation rates generally follow the Site U1385 planktic $\delta^{18} \mathrm{O}$, but whilst low sedimentation rates are broadly associated with higher planktic $\delta^{18} \mathrm{O}$ values (i.e. cooler climate) and vice versa over the older half of the record, the pattern clearly reverses at $\sim 900-890 \mathrm{ka}$ for the remainder of the record. The glacial maximum of MIS 22 and the early part of TX, in particular, show large sedimentation rates. Such spikes in sedimentation rate have also been observed in the directly dated sequence through TI in nearby core MD99-2334 (57). Broadly the opposite occurs during TXII. The reason for this reversal is unclear but could signal a change in the pattern of deep-ocean currents associated with the MPT.

\section{Identifying the start of Terminations XII and X}

Criteria for the timing of terminations vary $(5,9,13,26)$. In this study we focus firstly on the timing of the onset of terminations. For TXII and TX we identified this onset as the point where SSTs, planktic $\delta^{18} \mathrm{O}$ and $\mathrm{C}_{37: 4}$ values show evidence of deglacial meltwaters reaching the Iberian margin, which together provide firm evidence of the collapse of Northern Hemisphere ice sheets (terminal Heinrich events). For both TXII and TX, the Site U1385 benthic $\delta^{18} \mathrm{O}$ values also start their near-monotonic trajectory towards interglacial values at these positions. Such multi-proxy coherence provides firm constraints on the core-depth positions for both TXII and TX. The Site U1385 depth positions used for the start of TXII and TX are $100.56 \mathrm{~m}$ and $110.08 \mathrm{~m}$ (i.e. crmcd as defined in ref. 30) respectively. Ages interpolated from each age model are shown in Table S2. They clearly show that the model estimates are statistically indistinguishable (reduced chi-square statistic (MSWD) 0.47 , probability of fit 0.62 ; statistically significant at $p<0.05$ ). To calculate the 95\% age errors presented in Table S2, we combined in quadrature the age modelling uncertainty for each model simulation (using the larger value of the plus or minus errors) with a conservative estimate of the synchronization uncertainty of $2 \mathrm{kyr}$.

For the period covered by the Corchia speleothem record, we only focus on the full deglaciations of TX and TXII, which are well expressed in the two ocean records. We do not consider the 'skipped deglaciation' of TXI due to uncertainties in aligning the marine record to the Corchia $\delta^{18} \mathrm{O}$ over this time period. This is evident in the lower number of tuning points between 920 and $900 \mathrm{ka}$ (fig. S4b). Nevertheless, based on the Corchia-tuned ocean record, the skipped termination occurs at $\sim 914$ ka (Fig. 1), placing it $\sim$ one obliquity cycle from both TXII and TX. The reason for the mismatch between the speleothem and ocean records is not entirely clear; even the two planktic $\delta^{18} \mathrm{O}$ series show different patterns during this transition, making it very challenging for synchronisation.

\section{A register of termination timings and durations}

The following two sections provide supporting information for the data presented in Figure 3, which compares the phasing of astronomical and insolation metrics to the timing of radiometrically constrained terminations from the present study 
(TXII and TX) as well as those from previous studies $(15,16)$. As discussed in the main text, terminal Heinrich events intervals of extensive ice-rafting, freshwater incursion and cooling in the North Atlantic Ocean that occur during a termination - can be used to determine when TXII and TX commenced. The timing of Terminations I to VII (which includes two deglaciations (TIIIa and TVIIa) widely acknowledged as being large enough to be assigned 'termination status' - ref. 58), has been determined using speleothems from China. The $\delta^{18} \mathrm{O}$ of these speleothems is sensitive to changes in the status of the Asian Summer Monsoon. Terminal Heinrich events trigger large-scale changes in ocean and atmospheric circulation, including a southward migration of the Intertropical Convergence Zone (ITCZ), which is thought to be responsible for the increase in $\delta^{18} \mathrm{O}$ in Chinese speleothems during these events (59). These cause a weakening of the Asian Summer Monsoon (ASM) - so-called 'Weak Monsoon Intervals' (WMIs) (16) - although several mechanisms have been proposed (60). Precise U-Th chronologies at the initiation of WMIs provide accurate estimates of the onset of the terminations in which they are contained through alignment with the corresponding terminal Heinrich event recorded in North Atlantic ocean cores. In the case of TIIIa to TIV, marine proxies from drilling site ODP980 (61) are used for the alignment, whilst data from site (U1314; 62) are used for TV to TVII $(15,16)$. Chronologically well-constrained ocean and sea-level records through TI (63) and TII (64) support the veracity of Chinese speleothem $\delta^{18} \mathrm{O}$ to respond rapidly to the initiation of terminal Heinrich events, irrespective of the exact atmospheric teleconnections involved. Together with radiometrically (Table S4). Figure S7 shows the context of each of these termination onsets against the relevant North Atlantic ocean records $(61,62)$ as well as the LR04 benthic $\delta^{18} \mathrm{O}$ stack (4).

Determining the duration of each termination ideally requires a radiometric age estimate of when ice volume reached its minimum in the ensuing interglacial. For TI and TII, this is relatively straightforward due to the large number of U-Th ages on corals that constrain the age of the MIS 5e and MIS 1 sea-level high stands. We assign an age of $7 \mathrm{ka}$ for the end of TI based on the data compilation of (63), and an age of 129 ka for the end of TII based on evidence presented in ref. 64 (Table S3). For TIIIa to TVII, the issue is more challenging: the link between the status of the ASM and the attainment of minimum ice volume during the following interglacial is unclear, precluding the direct assignment of a speleothem age to the approximate position of the termination end in the ODP980 and U1314 ocean records or the LR04 benthic $\delta^{18} \mathrm{O}$. Instead, we identified the end of deglaciation as the point in the LR04 benthic $\delta^{18} \mathrm{O}$ stack where the first derivative of a two-point smoothing of the $\delta^{18} \mathrm{O}$ crosses the 'zero line' within the interglacial (i.e. where the direction of benthic $\delta^{18} \mathrm{O}$ change in successive data points through the deglaciation switches from positive to negative) and where the termination is obviously complete based on $\sim$ minimum benthic $\delta^{18} \mathrm{O}$ values (lower panels, fig. S7; Table S3). The age assigned to this point was adjusted by an amount equivalent to the difference between the LR04 and the speleothemderived ODP980 or U1314 benthic $\delta^{18} \mathrm{O}$ ages for the start of the termination; determining the position of this point on the 
LR04 stack from ODP980 and U1314 was relatively straightforward (fig. S7). Since the original age model of the LR04 stack is tied to assumptions based in orbital tuning for much of the time period we cover (5), we also estimated the timing of the completion of TIIIa to TVII using an alternative version of LR04 that is anchored to a depth-derived chronology (i.e. free of orbital-forcing assumptions) (17). These estimates are provided in the lower panel of Table S3.

Since we have radiometric age control on the U1385 benthic $\delta^{18} \mathrm{O}$ through TXII and TX, we assigned an age to their completion using similar principles to the above: we first applied a five-point smoothing (due to its higher resolution) to the $\mathrm{U} 1385$ benthic $\delta^{18} \mathrm{O}$ then identified the point through the termination where the first derivative (fig. S7) switches to negative. Synchronization of the speleothem and ocean records at the end of TX was somewhat more challenging because there is a short interval in the speleothem stack that is represented only by the low-resolution record from CD3, a slow-growing subaqueous speleothem (fig. S4a). This affects the positioning of the end of TX. However, our derived age estimate (864 ka), which indicates a termination of intermediate length ( $\sim 11 \mathrm{kyr})$, is consistent with the LR04 estimate of the duration of this termination $(\sim 12 \mathrm{kyr})$. Based on the termination commencement and completion ages graphically shown in fig. S7, the midpoint and duration for each termination can be derived (Table S3).

We should note that we considered assigning the end of each termination based on the LR04 threshold $\delta^{18} \mathrm{O}$ values used by ref. 1 in developing their register of interglacials. However, it is clear that deglaciation for most G-IG cycles continues well beyond the point where these thresholds are crossed and relying on these markers would significantly underestimate the termination duration.

\section{Orbital and insolation metrics for each termination}

We extracted orbital and insolation metrics at the onset, midpoint and completion ages for each termination (Table S4) to determine if phasing of precession and obliquity for TXII and TX is any different to the earlier terminations, and what factors (if any) control the duration of terminations. Polar plots (Fig. 3a-c, main text) of the phasing of precession and obliquity at each termination onset, midpoint and ending were compiled by converting the astronomical data from ref. 1 into degrees. Due to the unequal amplitude of these cycles, each half-precession and half-obliquity cycle was treated separately. Maximum obliquity and minimum precession (i.e. the point where both, individually, exert maximum influence on insolation at $65^{\circ} \mathrm{N}$ ) of each cycle were both referenced to $0^{\circ}$, and the preceding minimum obliquity and maximum precession were assigned a phase of $180^{\circ}$; intermediate values of both metrics were linearly interpolated. Due to their previous association as indices controlling terminations and the attainment of interglacial conditions, the caloric summer half-year insolation values at $65^{\circ} \mathrm{N}(9)$ and integrated summer energy $\left(>275 \mathrm{~W} / \mathrm{m}^{2}\right)$ at $65^{\circ} \mathrm{N}(17)$ were also extracted for the start, midpoint and end of each termination. Table S4 contains the metrics used to compile Figure 3. 
In Figure 4b, we compare termination midpoint ages and their uncertainties (see next paragraph) to the insolation forcing time series of ref. 13, which combines both precession and obliquity variability in equal amounts. Briefly, the forcing at time $t\left(\mathcal{F}_{t}\right)$ takes the form:

$$
\mathcal{F}_{t}=\alpha^{0.5} e_{t} \sin \left(\omega_{t}-\phi\right)+(1-\alpha)^{0.5} \varepsilon^{t}
$$

where $e$ is eccentricity, $\omega$ is the angle between the vernal equinox and perihelion and $\varepsilon$ is tilt (each normalised to zero mean and unit variance), $\phi$ is zero degrees and $a$ is $0.5(13,67)$.

Conservative age uncertainties for each termination were based around radiometric ages $(15,16)$ or model ages (this study) for each termination onset. The same uncertainty (as $\pm \mathrm{kyr}, 95 \%$ confidence limits) was assumed to apply for termination midpoints and completions, and are as follows: T1: 0.2 kyr; TII: 0.5 kyr; TIIa and TIII: 1 kyr; TIV: 2 kyr; TV: 2.5 kyr; TVI: 4 kyr; TVIIa: 5 kyr; TVII: 6 kyr; TX: 5 kyr; TXII: 5 kyr. To construct Figure 4c, we first used these radiometric age uncertainties to derive phase uncertainties for each termination. Probability distributions were then calculated for each of the three orbital metrics shown in Figure 4c and an error-weighted phase mean and (error-weighted) phase uncertainty derived (fig. S8). Two out of the 11 observations were rejected from the obliquity probability distributions whilst one was rejected from precession distributions; no outliers were rejected from the combined precession and obliquity metric (13) (fig. S8). 


\section{Additional references}

32. L. Piccini et al. The environmental features of the Monte Corchia cave system (Apuan Alps, central Italy) and their effects on speleothem growth. Int. J. Speleol. 37 (3), 153-172 (2008).

33. R.N. Drysdale et al. Precise microsampling of poorly laminated speleothems for U-series dating. Quat. Geochronol. 14, 38-47 (2012).

34. R.N. Drysdale et al. Partitioning of $\mathrm{Mg}, \mathrm{Sr}, \mathrm{Ba}$ and $\mathrm{U}$ into a subaqueous speleothem. Geochim. Cosmochim. Acta 264, 67-91 (2019).

35. C. Spötl, T.W. Vennemann. Continuous-flow isotope ratio mass spectrometric analysis of carbonate minerals. Rapid Commun. Mass Spectrom. 17, 1004-1006 (2003).

36. C. Spötl, C. Long-term performance of the Gasbench isotope ratio mass spectrometry system for the stable isotope analysis of carbonate microsamples. Rapid Commun. Mass Spectrom.25, 1683-1685 (2011).

37. M.D. Schmitz, B. Schoene. Derivation of isotope ratios, errors, and error correlations for U-Pb geochronology using ${ }^{205} \mathrm{~Pb}-{ }^{235} \mathrm{U}-\left({ }^{233} \mathrm{U}\right)$-spiked isotope dilution thermal ionization mass spectrometric data. Geochem. Geophys. Geosyst. 8, Q08006 (2007), doi.org/10.1029/2006GC001492.

38. D.A. Richards, S.H. Bottrell, R.A. Cliff, K. Ströhle, P.J. Rowe. U-Pb dating of a speleothem of Quaternary age. Geochim. Cosmochim. Acta 62, 3683-3688 (1998).

39. D.A. Richards, J.A. Dorale. U-series chronology of speleothems and palaeoclimate. Uranium-series geochemistry. Rev. Mineral. Geochem. 52, 407-460 (2003).

40. J. Hellstrom. Rapid and accurate U/Th dating using parallel ion-counting multi-collector ICP-MS. J. Anal. Atom. Spectrom. 18, 1346-1351 (2003).

41. E.J. Hendy et al. Assessing amino acid racemization variability in coral intra-crystalline protein for geochronological applications. Geochim. Cosmochim. Acta 86, 338-353 (2012).

42. D. Scholz, D. Hoffmann, J.C. Hellstrom, C. Bronk Ramsey. A comparison of different methods for speleothem age modelling. Quat. Geochron. 14, 94-104 (2012).

43. R. N. Drysdale, G. Zanchetta, J. C. Hellstrom, A. E. Fallick, J. X. Zhao. Stalagmite evidence for the onset of the last Interglacial in southern Europe at 129 ka. Geophys. Res. Lett. 32, L24708 (2005), doi.org/10.1029/2005GL024658.

44. J. Hellstrom. U-Th dating of speleothems with high initial ${ }^{230} \mathrm{Th}$ using stratigraphical constraint. Quat. Geochron. 1, 289-295.

45. A.H.L. Voelker et al. Mediterranean Outflow and surface water variability off southern Portugal during the early Pleistocene: A snapshot at Marine Isotope Stages 29 to 34 (1020-1135 ka) Glob. Planet. Change 133, 223-237 (2015). 
46. A.H.L. Voelker, A. Colman, G. Olack, J.J. Waniek, D. Hodell. Oxygen and hydrogen isotope signatures of Northeast Atlantic water masses. Deep Sea Research Part II: Top. Stud. Oceanogr. 116, 89-106 (2015).

47. A.H.L. Voelker et al. Data report: IODP Site U1387: the revised splice between Sections U1387B-18X-3 and U1387C-8R-3 (>171.6 mcd), In: D.A.V. Stow, F.J. Hernández-Molina, C.A. Alvarez Zarikian and the Expedition 339 Scientists (Eds.), Proceedings of the Integrated Ocean Drilling Program 339. Integrated Ocean Drilling Program Management International, Inc., Tokyo, pp. 1-11. (2018).

48. J. Villanueva, J.O. Grimalt, E. Cortijo, L. Vidal, L. Labeyrie. A biomarker approach to the organic matter deposited in the North Atlantic during the last climatic cycle. Geochim. Cosmochim. Acta 61, 4633-4646 (1997).

49. T. Rodrigues, A.H.L. Voelker, J.O. Grimalt, F. Abrantes, F. Naughton. Iberian Margin sea surface temperature during MIS 15 to 9 (580-300 ka): glacial suborbital variability versus interglacial stability. Paleocean. 26, PA1204 (2011), doi.org/10.1029/2010PA001927.

50. P.J. Müller, G. Kirst, G. Ruhland, I. von Storch, A. Rosell-Melé. Calibration of the alkenone paleotemperature index Uk'37 based on core-tops from the eastern South Atlantic and the global ocean $\left(60^{\circ} \mathrm{N}-60^{\circ} \mathrm{S}\right)$. Geochim. Cosmochim. Acta 62, 1757-1772 (1998).

51. F. Prahl, S.G. Wakeham. Calibration of unsaturation patterns in long-chain ketones compositions for palaeotemperature assessment. Nature 330, 367-369 (1987).

52. R.N. Drysdale et al. Stalagmite evidence for the precise timing of North Atlantic cold events during the early last glacial. Geology 35, 77-80 (2007).

53. Dansgaard, W. The ${ }^{18} \mathrm{O}$-abundance in fresh water. Geochim. Cosmochim. Acta 6 (5-6), 241-260 (1954).

54. J. Zhu et al. Investigating the direct meltwater effect in terrestrial oxygen-isotope paleoclimate records using an isotope-enabled Earth system model. Geophys. Res. Lett. 44, 6984-6992 (2017).

55. D. Paillard, L. Labeyrie, P. Yiou. Macintosh program performs time-series analysis. Eos 77, 379 (1996).

56. M. Blaauw, A.J. Christen. Flexible paleoclimate age-depth models using an autoregressive gamma process. Bayesian Anal. 6, 457 (2011).

57. L.C. Skinner, C. Waelbroeck, A.E. Scrivner, S.J. Fallon. Radiocarbon evidence for alternating northern and southern sources of ventilation of the deep Atlantic carbon pool during the last deglaciation. Proc. Natl. Acad. Sci. 111, 5480-5484 (2014).

58. Past Interglacials Working Group of PAGES. Interglacials of the last 800,000 years. Rev. Geophys. 54, doi:10.1002/2015RG000482.

59. G.H. Denton et al. The Last Glacial Termination. Science 328, 1652-1656 (2010). 
60. H. Zhang et al. East Asian hydroclimate modulated by the position of the westerlies during Termination I. Science 362, 580-583 (2018).

61. J.F. McManus, D.W. Oppo, J.L. Cullen. A 0.5-million-year record of millennial-scale climate variability in the North Atlantic. Science 283, 971-975 (1999).

62. M. Alonso-Garcia et al. Ocean circulation, ice sheet growth and interhemispheric coupling of millennial climate variability during the mid-Pleistocene (ca 800-400 ka). Quat. Sci. Rev. 30, 3234-3247 (2011).

63. K. Lambeck, H. Rouby, A. Purcell, Y. Sun, M. Sambridge. Sea level and global ice volumes from the Last Glacial maximum to the Holocene. Proc. Natl. Acad. Sci. 111, 15296-15303 (2014).

64. L. Menviel et al. The penultimate deglaciation: protocol for Paleoclimate Modelling Intercomparison Project (PMIP) phase 4 transient numerical simulations between 140 and 127 ka, version 1.0. Geosci. Model Dev.12, 3649-3685 (2019).

65. K.R. Ludwig. Isoplot/Ex, rev. 2.49. A geochronological toolkit for Microsoft Excel. (Berkeley Geochronology Center, Berkley, USA. Special Publication 1a (2001). 

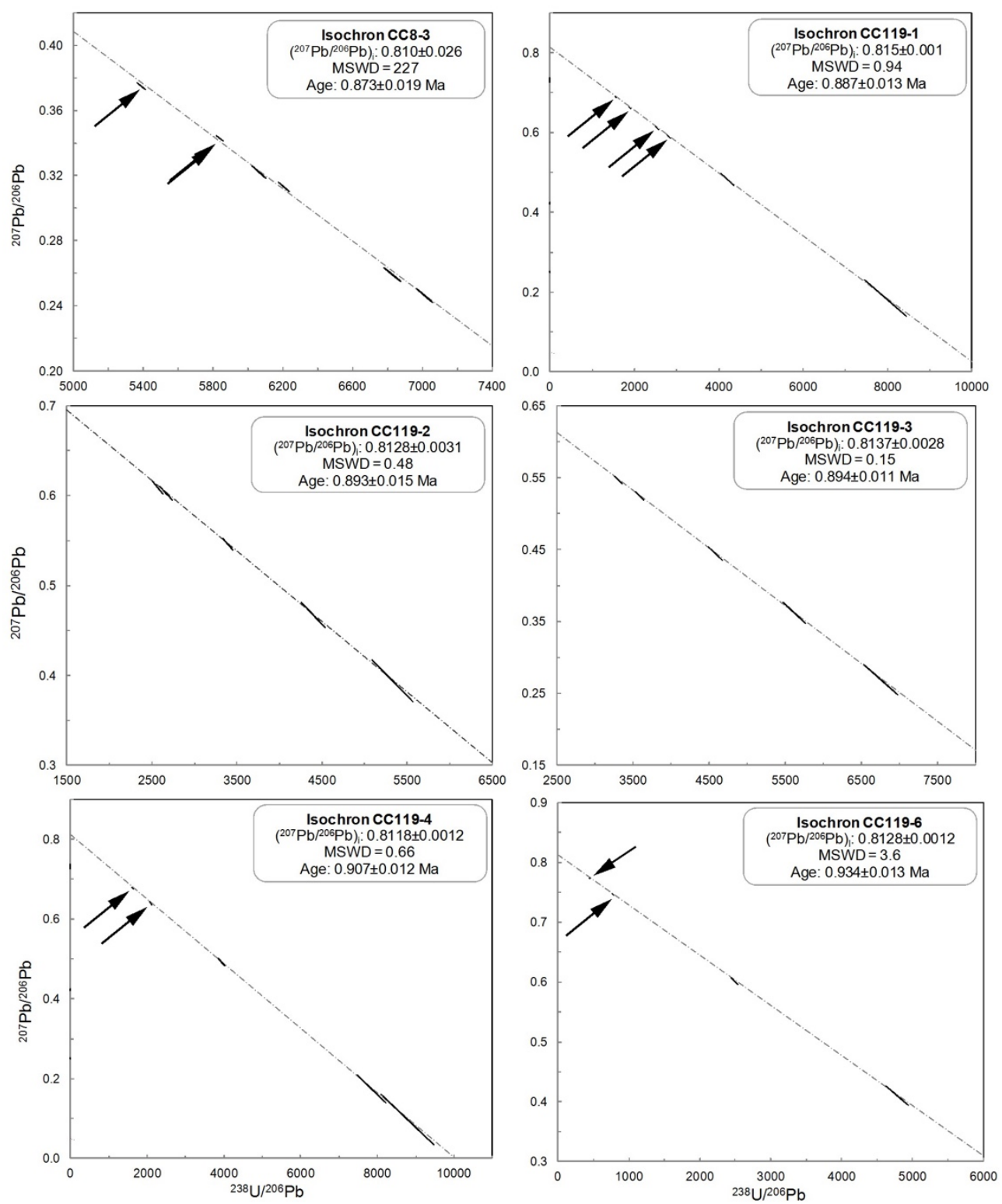

463

Fig. S1. Plots of CC8-3 and all CC119 isochrons. All ages are corrected for initial disequilibrium in the U-Pb decay chain. 

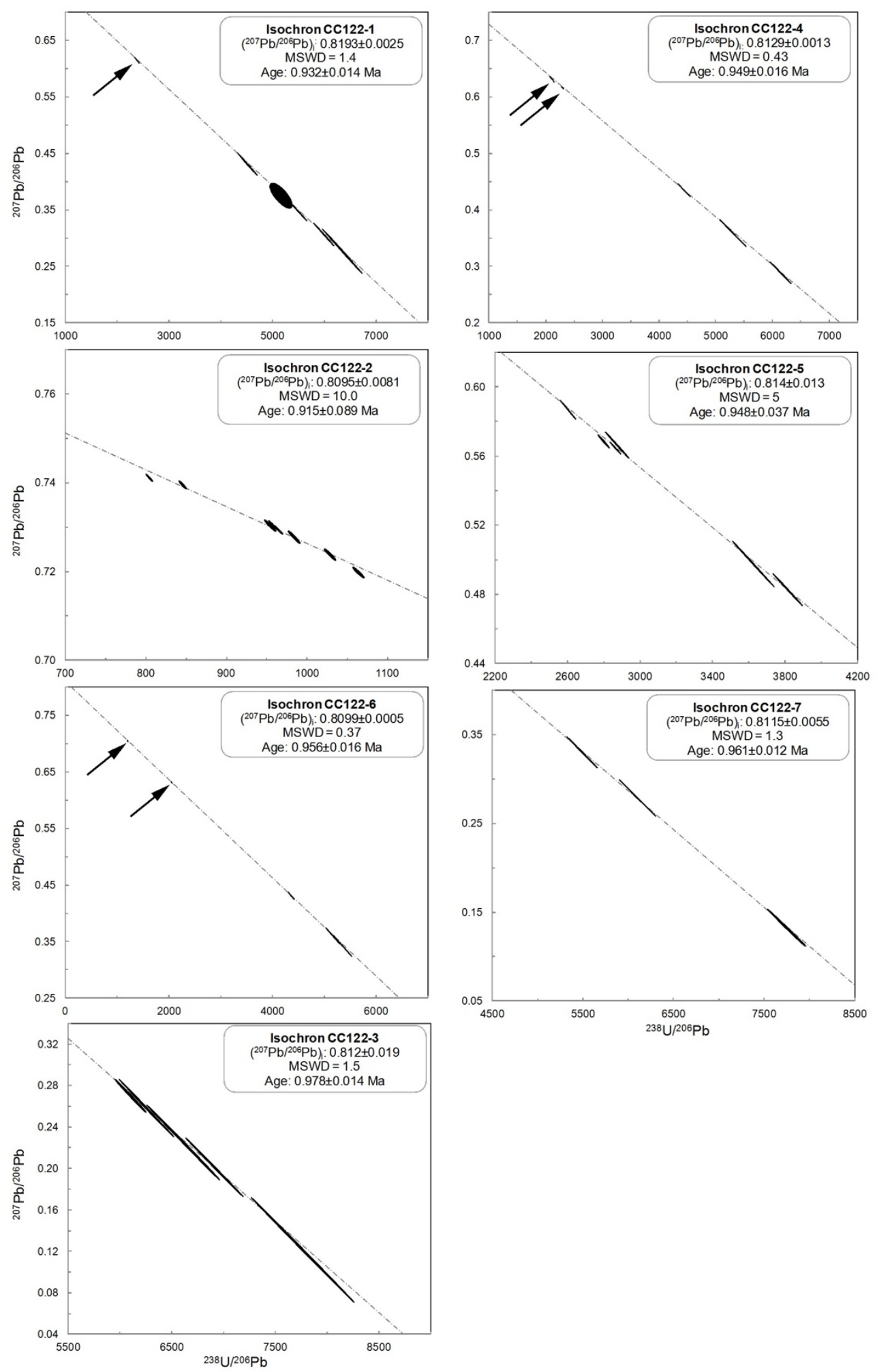

469 Fig. S1. (Cont.) Plots for $\mathrm{CC} 122$ isochrons. Based on these measurements an initial ${ }^{207} \mathrm{~Pb} /{ }^{206} \mathrm{~Pb}$ ratio was estimated and used to calculate single aliquot ages. 


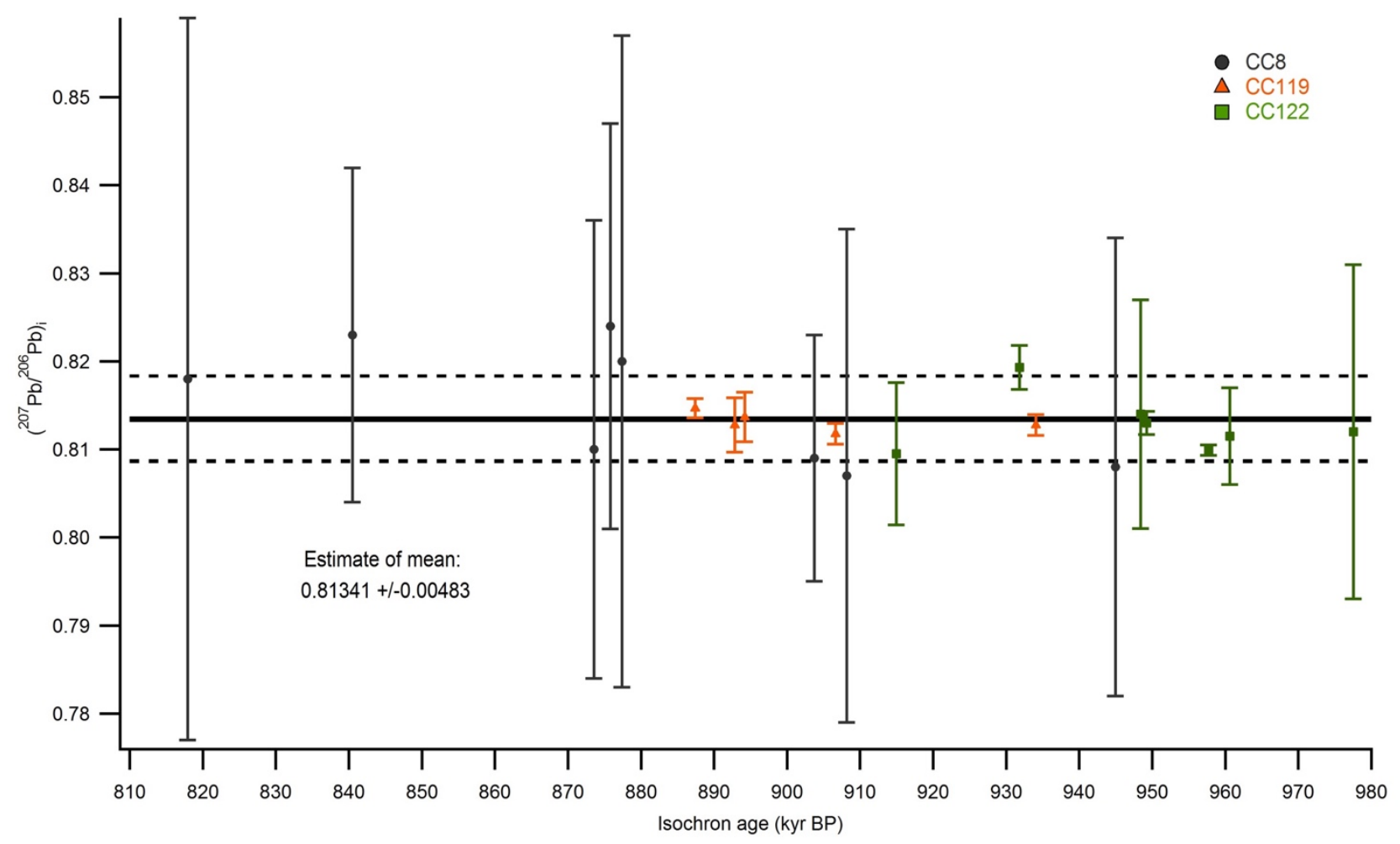

Fig. S2. Initial ${ }^{207} \mathrm{~Pb} / 206 \mathrm{~Pb}$ ratio for all 20 full isochrons determined in this study suggests a stable and consistent source of common $\mathrm{Pb}$. The estimated mean is indicated with a thick horizontal black line while dashed lines present its $95 \%$ uncertainty. 
a

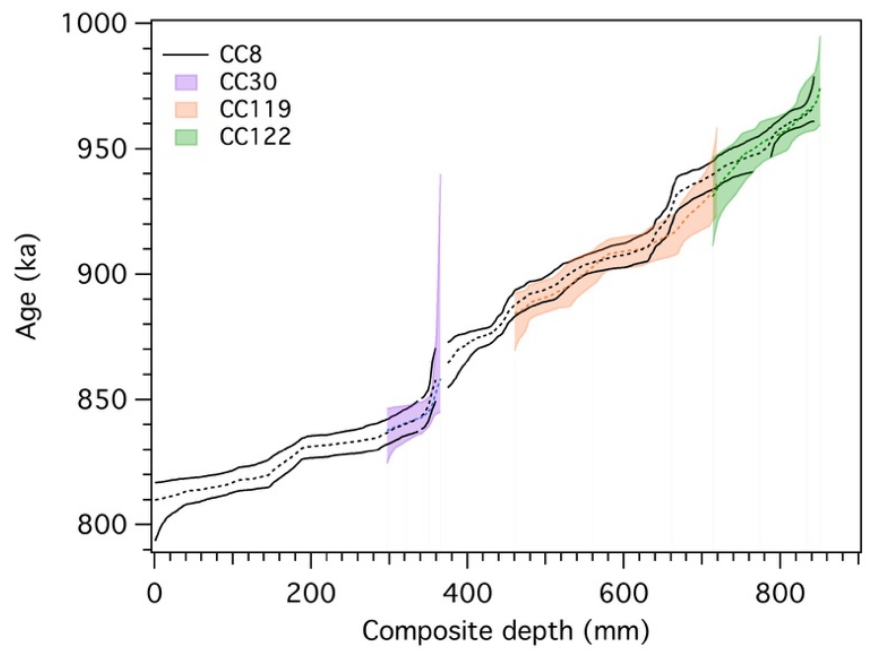

b

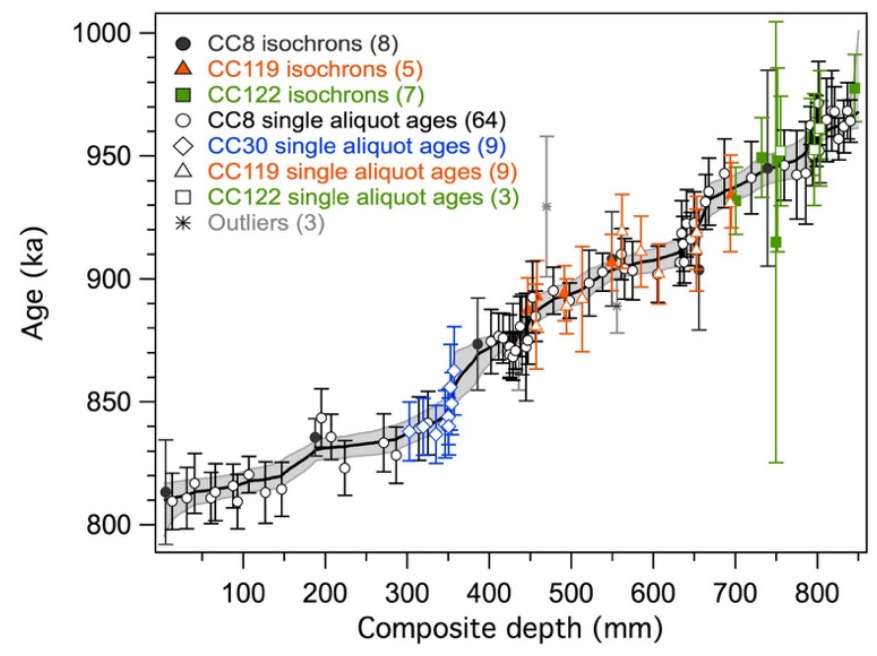

C

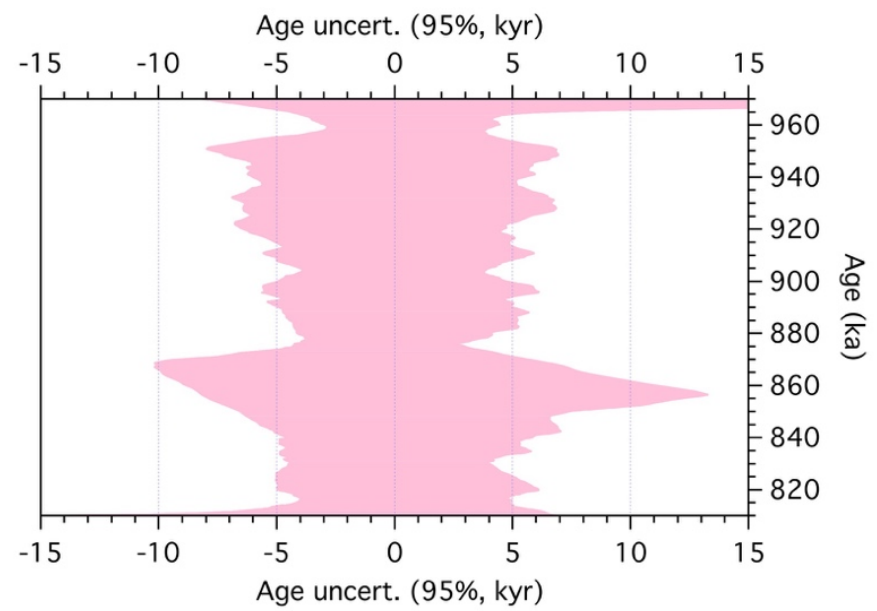

Fig. S3. (a) Individual age-depth model 95\% uncertainty envelopes for Corchia speleothems CC8 (black lines), CC30 (purple shading), CC119 (orange shading) and CC122 (green shading). All speleothem data are plotted on the composite depth scale based on the cross-tuning of their respective $\delta^{18} \mathrm{O}$ profiles (see fig. S4 and Materials and Methods for details). (b) The composite age-depth model produced from 20 isochron and 85 single-aliquot U-Pb ages. The three outliers shown are single-aliquot ages and are not included in the age-depth model. The median model age is represented by the solid black line. The grey shaded area is the 95\% uncertainty envelope. (c) Age-for-age uncertainty based on the age model shown in (b). 

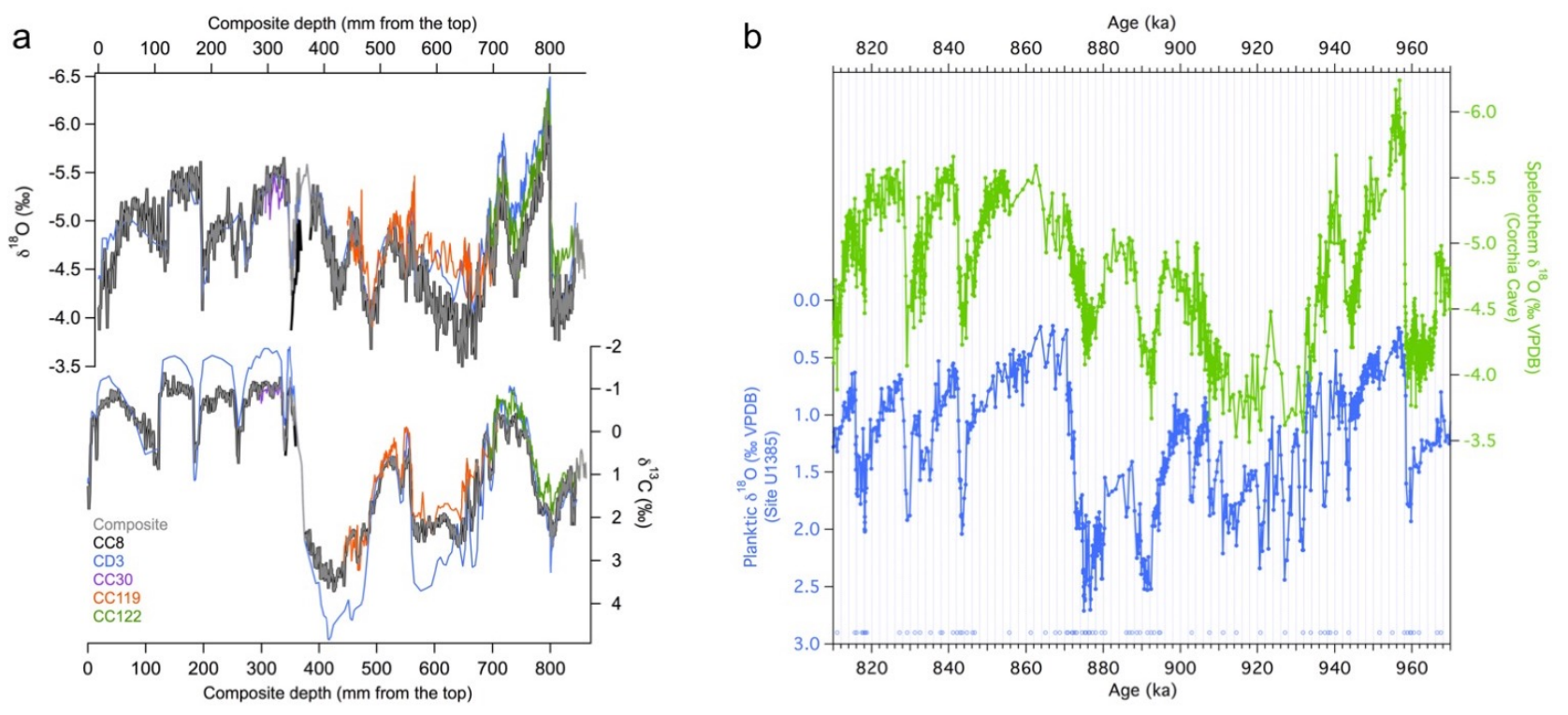

Fig. S4. (a) Stable isotopes series for all speleothems (CC8 in black; CC30 in purple; CC119 in orange; CC122 in green and $\mathrm{CD} 3$ in light blue) translated onto the composite depth scale using $\delta^{18} \mathrm{O}$ and $\delta^{13} \mathrm{C}$ as proxies for cross tuning. The composite profiles are shown in grey. (b) Results of the synchronisation of site U1385 marine and to the Corchia Cave speleothem stack shown in (a). The synchronisation was achieved by correlating the speleothem $\delta^{18} \mathrm{O}$ and planktic $\delta^{18} \mathrm{O}$ records, and was implemented in AnalySeries (55). The plots are shown on the Corchia Cave U-Pb chronology. The open circles represent the tuning points used. 

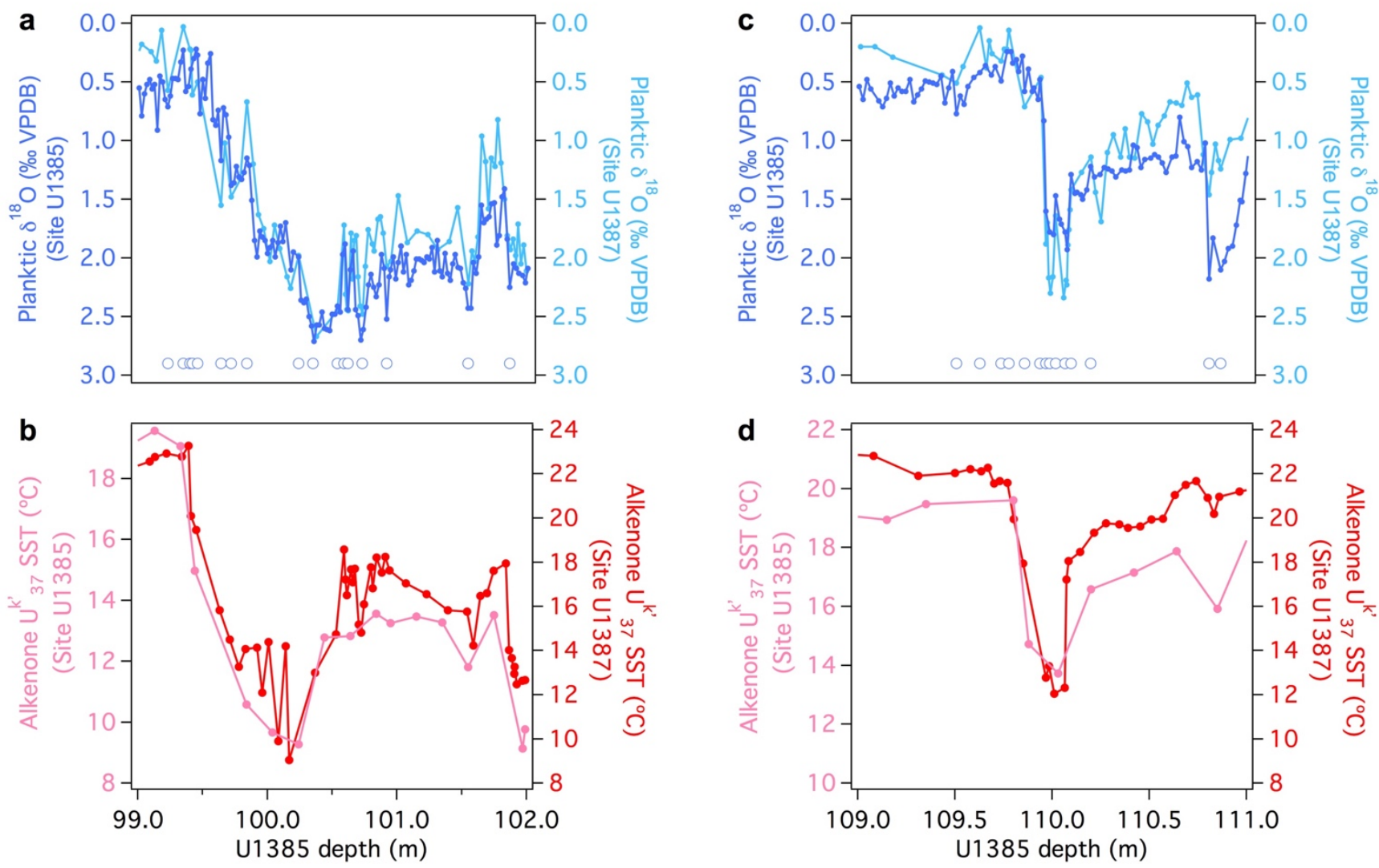

Fig. S5. Results of the synchronisation of ocean sites U1385 and U1387 for Termination X (a, b) and XII (c, d). The tuning was implemented in AnalySeries (55) using the two planktic $\delta^{18} \mathrm{O}$ records. The corresponding alkenone $\mathrm{U}^{\mathrm{k}}{ }_{37} \mathrm{SST}$ series from each core are also shown. Each plot is displayed on the depth scale of U1385. The open circles are the tuning points used. 


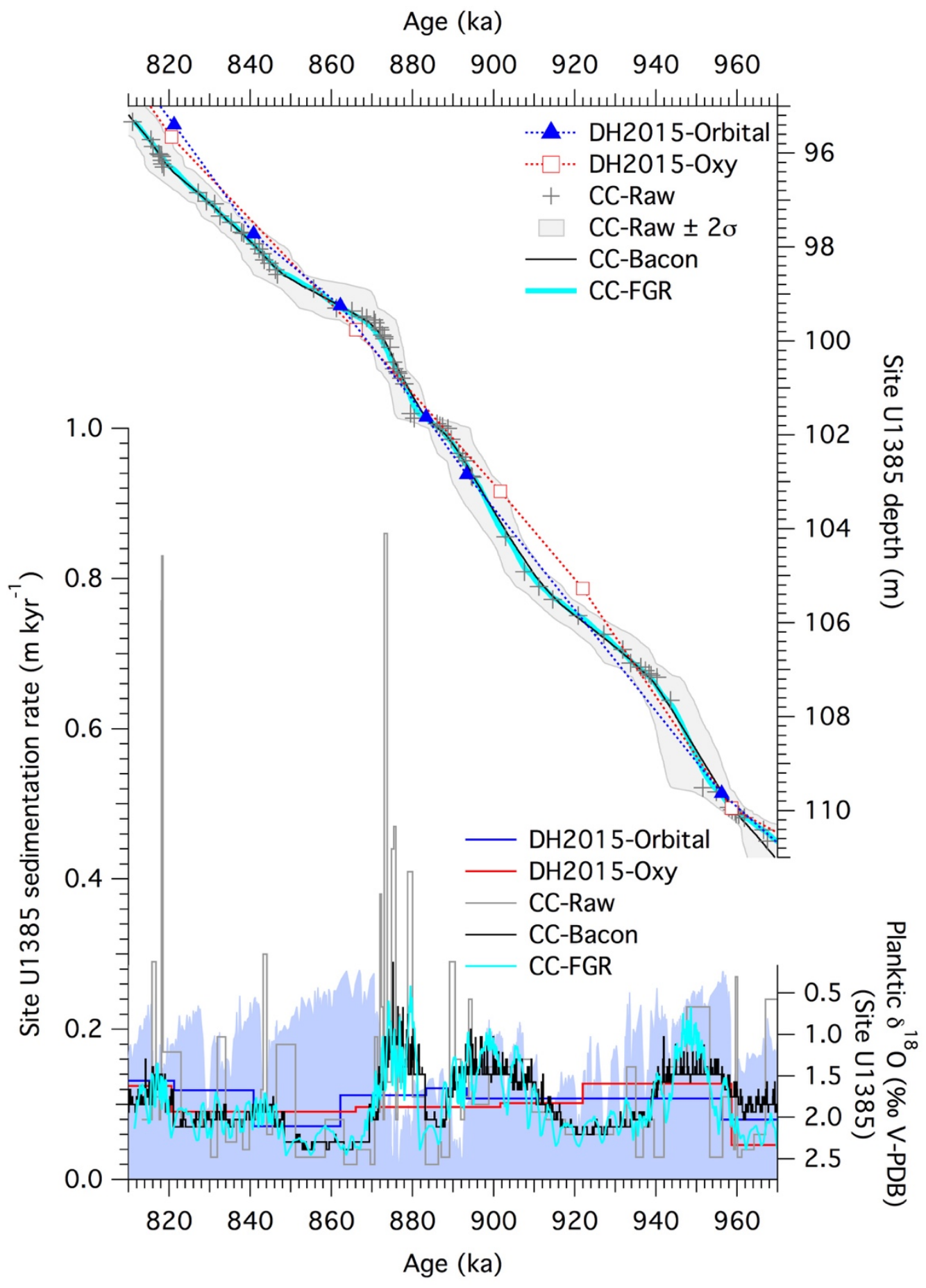

Fig. S6. Age models (upper panel) and sedimentation rates (lower panel) for Site U1385 using the published DH2015oxy and DH2015-orbital models (30), and the CC-Raw, CC-Bacon and CC-FGR outputs derived from this study. The planktic $\delta^{18} \mathrm{O}$ data are also shown (lower panel) on the CC-Raw age model for comparison with sedimentation rates. See Materials and Methods for an explanation of these models. 

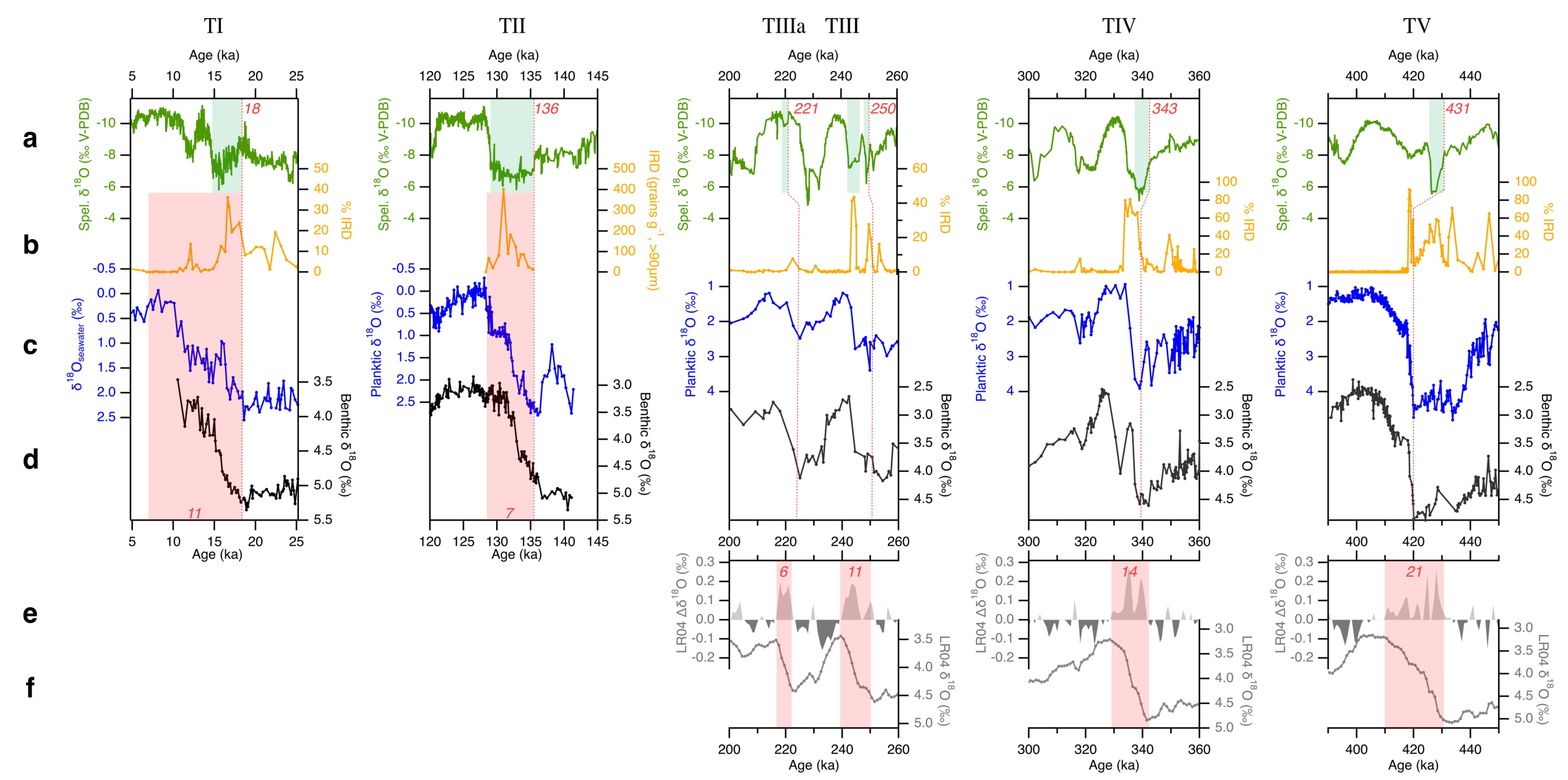


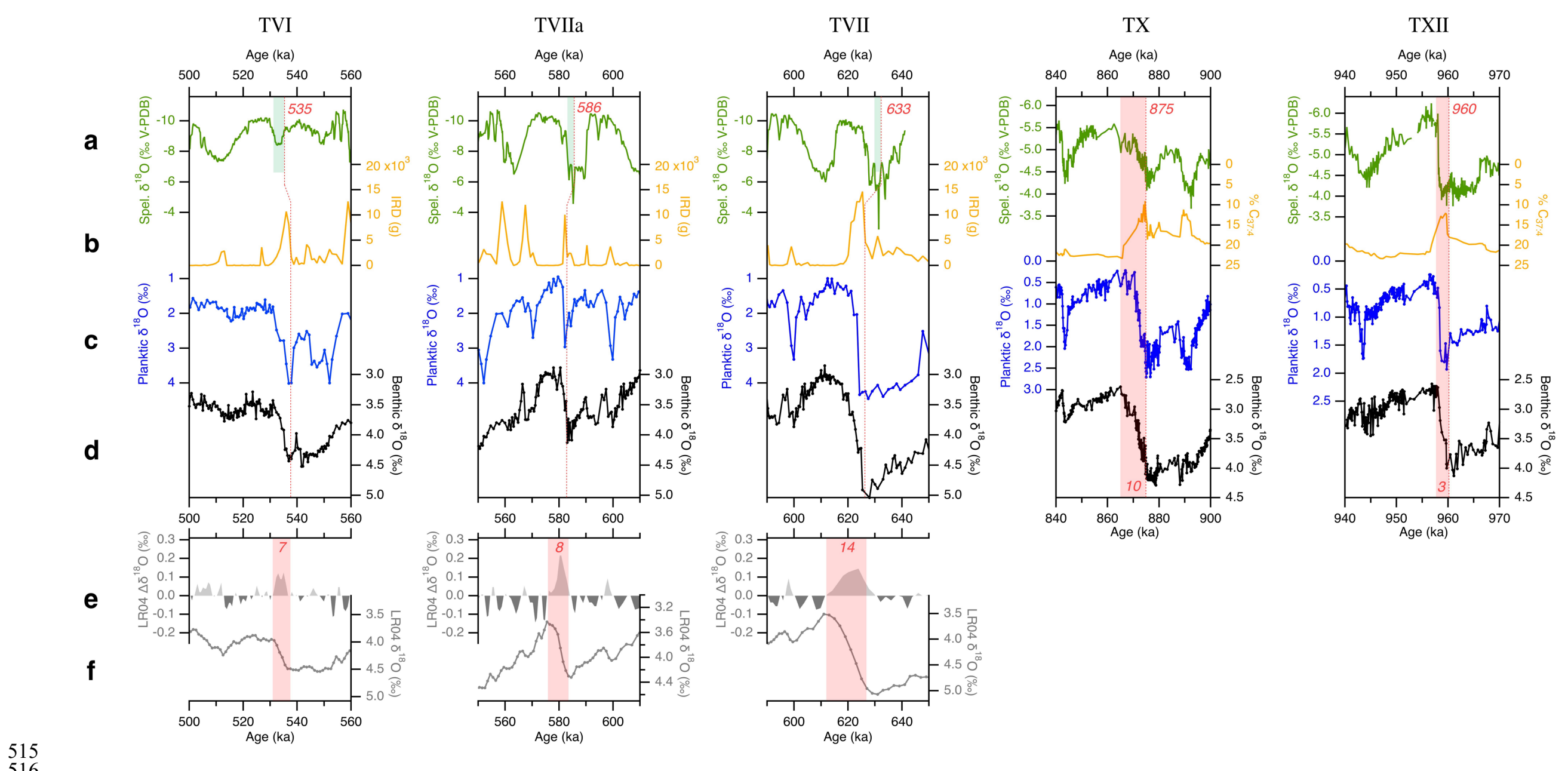


Fig. S7. Speleothem-based radiometric ages for the commencement and duration of TI - TVII and TX and TXII. (a) Speleothem records (green curves) from Hulu, Dongge and

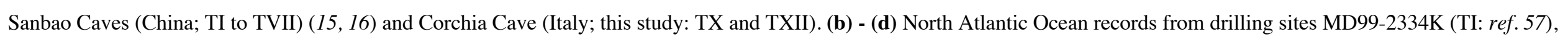

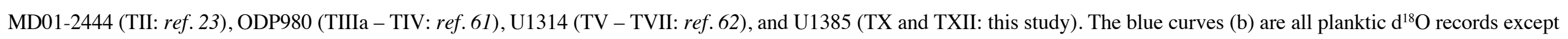
that for TI, which shows the temperature-corrected (using $\mathrm{Mg} / \mathrm{Ca}$ ) surface ocean-water $\delta^{18} \mathrm{O}(57)$. The orange curves (c) show ice-rafted debris concentrations for all terminations except TX and TXII, for which the Uk' $\mathrm{C}_{37: 4}$ freshwater proxy is shown instead. The black curves (d) show benthic $\mathrm{d}^{18} \mathrm{O}$ through each termination. (e) - (f) For TIIIa to TVII, the

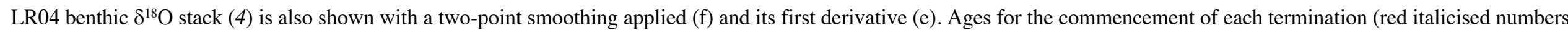

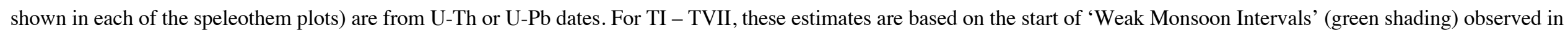

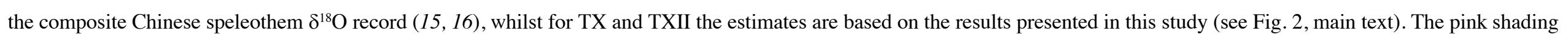

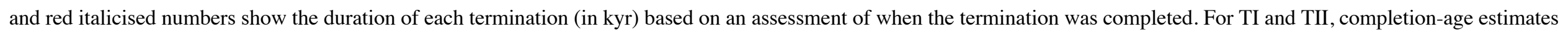
are sourced from data presented in ref. 63 and ref. 64 respectively. For TIIIa to TVII, the age at the point where the first derivative of the LR04 benthic $\delta^{18} \mathrm{O}$ series $\left(\Delta \delta^{18} \mathrm{O} / \Delta \mathrm{T}\right)$

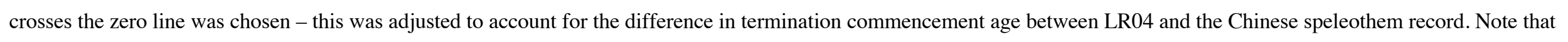

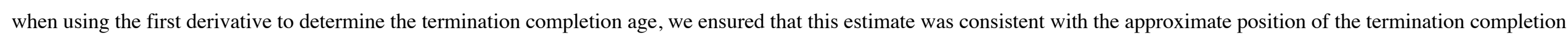

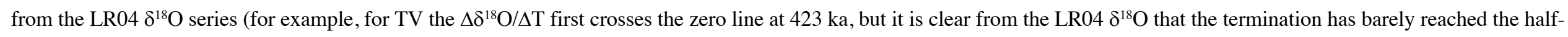
way point). 

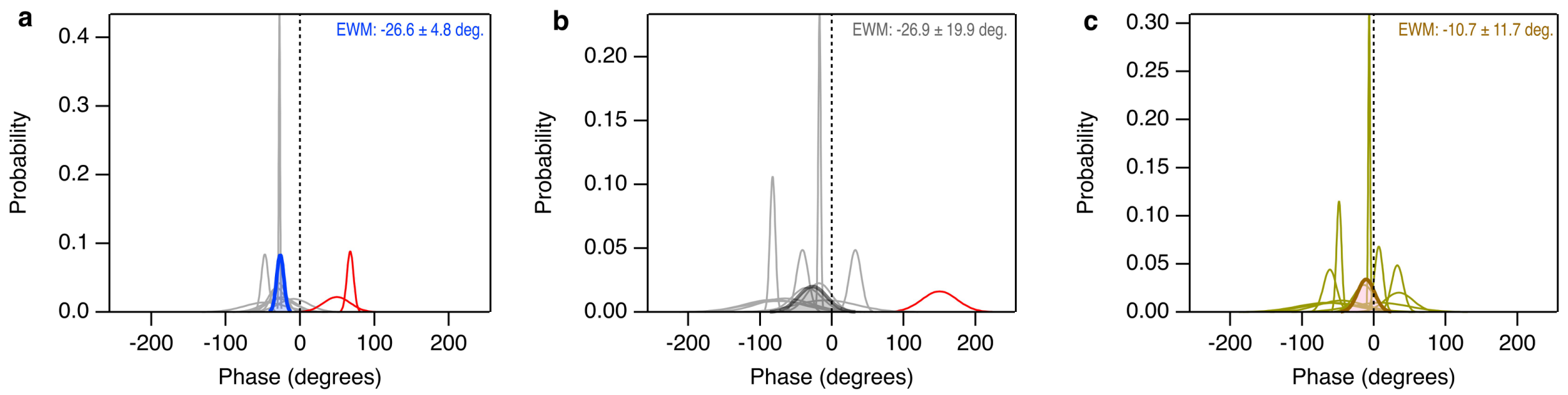

Fig. S8: Phase probability distributions for individual terminations (light grey) for (a) obliquity, (b) precession and (c) an insolation forcing metric combining obliquity and precession (13). Phase uncertainties were calculated from the corresponding 95\% age uncertainties (see SOM text). The error-weighted mean (EWM) phase and uncertainty is shown for each metric and is graphically represented by the blue, grey and brown distributions. Individual-outlier probability distributions are shown in red (two for obliquity and one for precession) and have been excluded from the error-weighted-mean calculations (implemented in using Isoplot (65)). 
Table S1. U-Pb age data.

539 U-Pb dating results for isochron and single-aliquot analyses performed on CC8, CC30, CC119 and CC122 stalagmites.

\begin{tabular}{|c|c|c|c|c|c|c|c|c|}
\hline Sample ID & $\begin{array}{l}\text { Depth }^{¥} \\
\text { from top } \\
\text { (mm) } \\
(100 \% \\
\text { uncert.) }\end{array}$ & $\begin{array}{l}\text { Total } \\
\mathrm{Pb} \\
(\mathrm{ppb})\end{array}$ & $\underset{(\mathrm{ppb})}{\mathrm{U}}$ & $\begin{array}{c}{ }^{238} \mathrm{U} /{ }^{206} \mathrm{~Pb} \\
(2 \sigma \text { error in \%) }\end{array}$ & $\begin{array}{c}{ }^{207} \mathrm{~Pb} /{ }^{206} \mathrm{~Pb} \\
(2 \sigma \text { error in \%) }\end{array}$ & MSWD $^{*}$ & $\begin{array}{c}\left({ }^{234} \mathrm{U} /{ }^{238} \mathrm{U}\right)_{\text {measured }} \\
( \pm 95 \% \text { uncertainty) }\end{array}$ & $\begin{array}{c}\text { Age (Ma) } \\
\text { corrected for } \\
\left({ }^{234} U /{ }^{238} U\right)_{\text {initia }} \\
( \pm 2 \sigma \text { error })\end{array}$ \\
\hline \multicolumn{9}{|c|}{ Isochron analyses } \\
\hline CC8-3§ & $385.6(4.0)$ & & & & & 227 & $0.9788(0.0015)$ & $0.874(0.019)$ \\
\hline CC8-3-1 & & 2.29 & 7857 & $6060.97(0.53)$ & $0.323(0.931)$ & & & \\
\hline $\mathrm{CC} 8-3-2$ & & 2.35 & 7489 & $5836.35(0.29)$ & $0.343(0.424)$ & & & \\
\hline CC8-3-3 & & 1.54 & 7103 & $7011.64(0.54)$ & $0.247(1.400)$ & & & \\
\hline CC8-3-4 & & 1.60 & 6965 & $6827.80(0.57)$ & $0.260(1.350)$ & & & \\
\hline CC8-3-5 & & 2.14 & 7653 & $6203.86(0.41)$ & $0.314(0.739)$ & & & \\
\hline $\mathrm{CC} 8-3-6$ & & 2.69 & 7469 & $5385.32(0.36)$ & $0.375(0.482)$ & & & \\
\hline CC119-1 & $447.0(5.0)$ & & & & & 0.94 & $0.9722(0.0018)$ & $0.887(0.013)$ \\
\hline CC119-1-1 & & 2.68 & 4698 & $4196.47(3.07)$ & $0.484(2.701)$ & & & \\
\hline CC119-1-3 & & 4.62 & 4870 & $2819.72(1.12)$ & $0.592(0.597)$ & & & \\
\hline CC119-1-5 & & 5.37 & 4969 & $2541.47(1.10)$ & $0.614(0.526)$ & & & \\
\hline CC119-1-6 & & 7.79 & 5110 & $1899.71(0.73)$ & $0.665(0.268)$ & & & \\
\hline CC119-1-9 & & 9.66 & 5016 & $1547.79(0.61)$ & $0.692(0.190)$ & & & \\
\hline CC119-1-12 & & 0.87 & 4590 & $7946.35(5.16)$ & $0.186(20.032)$ & & & \\
\hline CC119-2 & $457.9(5.0)$ & & & & & 0.48 & $0.9708(0.0017)$ & $0.893(0.015)$ \\
\hline CC119-2-2 & & 5.17 & 4800 & $2569.91(2.07)$ & $0.610(1.010)$ & & & \\
\hline CC119-2-4 & & 5.05 & 5017 & $2695.93(1.37)$ & $0.601(0.702)$ & & & \\
\hline CC119-2-7 & & 5.47 & 5285 & $2635.16(1.31)$ & $0.607(0.652)$ & & & \\
\hline CC119-2-10 & & 4.06 & 5419 & $3391.08(1.45)$ & $0.547(0.958)$ & & & \\
\hline CC119-2-12 & & 2.90 & 5465 & $4397.10(2.65)$ & $0.468(2.490)$ & & & \\
\hline CC119-2-14 & & 2.02 & 5055 & $5327.28(3.73)$ & $0.395(4.849)$ & & & \\
\hline CC119-3 & $491.3(5.0)$ & & & & & 0.15 & $0.9743(0.0016)$ & $0.894(0.011)$ \\
\hline CC119-3-2 & & 2.12 & 8442 & $6758.46(2.72)$ & $0.270(6.427)$ & & & \\
\hline CC119-3-4 & & 4.23 & 8724 & $4581.01(1.60)$ & $0.446(1.663)$ & & & \\
\hline CC119-3-6 & & 5.80 & 7538 & $3300.15(1.32)$ & $0.549(0.866)$ & & & \\
\hline CC119-3-8 & & 5.06 & 7338 & $3580.97(1.26)$ & $0.526(0.918)$ & & & \\
\hline CC119-3-11 & & 3.09 & 8801 & $5618.58(2.20)$ & $0.363(3.306)$ & & & \\
\hline CC119-4 & $549(5.0)$ & & & & & 0.66 & $0.9741(0.0016)$ & $0.907(0.012)$ \\
\hline CC119-4-1 & & 0.80 & 5477 & $8776.15(6.39)$ & $0.100(51.873)$ & & & \\
\hline CC119-4-3 & & 1.10 & 6025 & $7845.43(3.88)$ & $0.176(16.178)$ & & & \\
\hline CC119-4-5 & & 3.93 & 6475 & $3931.95(1.86)$ & $0.494(1.562)$ & & & \\
\hline CC119-4-8 & & 8.38 & 6153 & $2089.66(1.37)$ & $0.642(0.567)$ & & & \\
\hline CC119-4-12 & & 10.19 & 5605 & $1622.55(0.85)$ & $0.680(0.285)$ & & & \\
\hline
\end{tabular}


540

\begin{tabular}{|c|c|c|c|c|c|c|c|c|}
\hline Sample ID & $\begin{array}{l}\text { Depth } \\
\text { from top } \\
(\mathrm{mm}) \\
(100 \% \\
\text { uncert.) }\end{array}$ & $\begin{array}{l}\text { Total } \\
\mathrm{Pb} \\
(\mathrm{ppb})\end{array}$ & $\begin{array}{c}\mathrm{U} \\
(\mathrm{ppb})\end{array}$ & $\begin{array}{c}{ }^{238} \mathrm{U} /{ }^{206} \mathrm{~Pb} \\
(2 \sigma \text { error in } \%)\end{array}$ & $\begin{array}{c}{ }^{207} \mathrm{~Pb} /{ }^{206} \mathrm{~Pb} \\
(2 \sigma \text { error in } \%)\end{array}$ & MSWD $^{*}$ & $\begin{array}{c}\left({ }^{234} U /{ }^{238} U\right)_{\text {measured }} \\
( \pm 95 \% \text { uncertainty) }\end{array}$ & $\begin{array}{c}\text { Age }(\mathrm{Ma}) \\
\text { corrected for } \\
\left({ }^{234} U /{ }^{238} U\right)_{\text {initial }} \\
( \pm 2 \sigma \text { error })\end{array}$ \\
\hline \multicolumn{9}{|c|}{ Isochron analyses (continued) } \\
\hline CC119-6 & $695.2(5.0)$ & & & & & 3.6 & $0.9756(0.0016)$ & $0.934(0.013)$ \\
\hline CC119-6-2 & & 2.41 & 5361 & $4781.96(2.74)$ & $0.412(3.300)$ & & & \\
\hline CC119-6-4 & & 32.67 & 4554 & $449.91(0.28)$ & $0.775(0.057)$ & & & \\
\hline CC119-6-6 & & 47.81 & 4099 & $281.01(0.21)$ & $0.790(0.027)$ & & & \\
\hline CC119-6-8 & & 42.49 & 4158 & $319.80(0.24)$ & $0.786(0.033)$ & & & \\
\hline CC119-6-10 & & 19.69 & 4830 & $775.56(0.71)$ & $0.748(0.152)$ & & & \\
\hline CC119-6-12 & & 5.79 & 5286 & $2489.53(1.58)$ & $0.602(0.801)$ & & & \\
\hline CC122-1 & $700.2(5.0)$ & & & & & 1.4 & $0.9773(0.0019)$ & $0.932(0.014)$ \\
\hline CC122-1-2 & & 1.78 & 4511 & $5165.31(3.35)$ & $0.376(4.685)$ & & & \\
\hline CC122-1-4 & & 1.82 & 5083 & $5472.11(2.85)$ & $0.351(4.530)$ & & & \\
\hline CC122-1-5 & & 2.56 & 5246 & $4517.17(2.51)$ & $0.431(2.770)$ & & & \\
\hline $\mathrm{CC} 122-1-6$ & & 2.59 & 5205 & $4512.01(3.42)$ & $0.432(3.780)$ & & & \\
\hline $\mathrm{CC} 122-1-8$ & & 1.59 & 5261 & $5988.35(2.68)$ & $0.308(5.241)$ & & & \\
\hline CC122-1-10 & & 1.44 & 5395 & $6446.17(3.67)$ & $0.268(8.777)$ & & & \\
\hline CC122-1-12 & & 1.48 & 5161 & $6243.92(3.74)$ & $0.289(8.016)$ & & & \\
\hline CC122-1-14 & & 5.04 & 4337 & $2380.72(1.61)$ & $0.616(0.763)$ & & & \\
\hline CC122-4 & $732.3(5.0)$ & & & & & 0.43 & $0.9756(0.0019)$ & $0.949(0.016)$ \\
\hline CC122-4-1 & & 1.74 & 6120 & $6147.11(2.50)$ & 0.289 (5.347) & & & \\
\hline CC122-4-3 & & 9.29 & 7798 & $2299.84(0.66)$ & $0.617(0.312)$ & & & \\
\hline CC122-4-6 & & 9.85 & 7484 & $2125.97(1.04)$ & $0.632(0.458)$ & & & \\
\hline CC122-4-8 & & 10.02 & 7466 & $2089.48(0.90)$ & $0.635(0.387)$ & & & \\
\hline CC122-4-10 & & 3.61 & 7290 & $4441.63(1.96)$ & $0.435(2.137)$ & & & \\
\hline CC122-4-12 & & 2.13 & 5619 & $5308.06(3.56)$ & $0.360(5.430)$ & & & \\
\hline CC122-2 & $749.6(5.0)$ & & & & & 10 & $0.9775(0.0014)$ & $0.915(0.090)$ \\
\hline $\mathrm{CC} 122-2-2$ & & 16.15 & 5391 & $1028.52(0.57)$ & $0.724(0.147)$ & & & \\
\hline $\mathrm{CC} 122-2-4$ & & 19.58 & 5298 & $845.46(0.43)$ & $0.740(0.096)$ & & & \\
\hline $\mathrm{CC} 122-2-6$ & & 16.62 & 5180 & $964.40(0.47)$ & $0.730(0.112)$ & & & \\
\hline CC122-2-8 & & 16.00 & 4924 & $954.46(0.60)$ & $0.730(0.145)$ & & & \\
\hline CC122-2-10 & & 13.88 & 4817 & $1063.97(0.53)$ & $0.720(0.141)$ & & & \\
\hline CC122-2-12 & & 15.04 & 4782 & $983.80(0.65)$ & $0.728(0.158)$ & & & \\
\hline CC122-2-14 & & 18.39 & 4724 & $804.31(0.43)$ & $0.741(0.095)$ & & & \\
\hline CC122-2-16 & & 15.28 & 4723 & $958.14(0.51)$ & $0.731(0.124)$ & & & \\
\hline
\end{tabular}




\begin{tabular}{|c|c|c|c|c|c|c|c|c|}
\hline Sample ID & $\begin{array}{c}\text { Depth } \\
\text { from top } \\
(\mathrm{mm}) \\
(100 \% \\
\text { uncert.) }\end{array}$ & $\begin{array}{l}\text { Total } \\
\mathrm{Pb} \\
(\mathrm{ppb})\end{array}$ & $\begin{array}{c}\mathrm{U} \\
(\mathrm{ppb})\end{array}$ & $\begin{array}{c}{ }^{238} \mathrm{U} /{ }^{206} \mathrm{~Pb} \\
(2 \sigma \text { error in \%) }\end{array}$ & $\begin{array}{c}{ }^{207} \mathrm{~Pb} /{ }^{206} \mathrm{~Pb} \\
(2 \sigma \text { error in } \%)\end{array}$ & $\mathrm{MSWD}^{*}$ & $\begin{array}{c}\left({ }^{234} U /{ }^{238} U\right)_{\text {measured }} \\
( \pm 95 \% \text { uncertainty })\end{array}$ & $\begin{array}{c}\text { Age (Ma) } \\
\text { corrected for } \\
\left({ }^{234} U^{238} U\right)_{\text {initial }} \\
( \pm 2 \sigma \text { error })\end{array}$ \\
\hline \multicolumn{9}{|c|}{ Isochron analyses (continued) } \\
\hline $\mathrm{CC122-5}$ & $751.3(5.0)$ & & & & & 5 & $0.9785(0.0016)$ & $0.948(0.037)$ \\
\hline $\mathrm{CC} 122-5-2$ & & 4.50 & 6720 & $3625.62(2.62)$ & $0.498(2.159)$ & & & \\
\hline $\mathrm{CC} 122-5-3$ & & 5.98 & 6554 & $2873.07(1.82)$ & $0.567(1.098)$ & & & \\
\hline $\mathrm{CC} 122-5-5$ & & 4.18 & 6790 & $3814.85(1.78)$ & $0.483(1.573)$ & & & \\
\hline $\mathrm{CC} 122-5-6$ & & 6.38 & 6890 & $2799.26(0.94)$ & $0.569(0.556)$ & & & \\
\hline $\mathrm{CC} 122-5-7$ & & 6.40 & 7106 & $2862.17(0.86)$ & $0.565(0.519)$ & & & \\
\hline CC122-5-9 & & 7.49 & 7307 & $2602.10(1.38)$ & $0.587(0.753)$ & & & \\
\hline CC122-6 & $792.1(5.0)$ & & & & & 0.37 & $0.9780(0.0019)$ & $0.958(0.016)$ \\
\hline $\mathrm{CC} 122-6-2$ & & 2.74 & 7589 & $5354.55(2.78)$ & $0.344(4.570)$ & & & \\
\hline $\mathrm{CC} 122-6-5$ & & 4.22 & 8515 & $4352.59(1.10)$ & $0.432(1.208)$ & & & \\
\hline $\mathrm{CC} 122-6-9$ & & 20.94 & 8309 & $1196.49(0.39)$ & $0.706(0.110)$ & & & \\
\hline CC122-6-11 & & 11.96 & 8783 & $2044.34(0.54)$ & $0.633(0.230)$ & & & \\
\hline CC122-6-14 & & 2.87 & 7526 & $5164.95(2.10)$ & $0.362(3.182)$ & & & \\
\hline CC122-7 & $804.7(5.0)$ & & & & & 1.3 & $0.9784(0.0015)$ & $0.961(0.012)$ \\
\hline $\mathrm{CC} 122-7-2$ & & 2.60 & 7559 & $5459.44(2.01)$ & $0.334(3.452)$ & & & \\
\hline $\mathrm{CC} 122-7-4$ & & 2.50 & 7544 & $5540.20(1.67)$ & $0.326(2.989)$ & & & \\
\hline CC122-7-7 & & 1.38 & 8693 & $7746.63(2.19)$ & $0.133(12.709)$ & & & \\
\hline CC122-7-10 & & 1.25 & 8007 & $7781.12(1.91)$ & $0.131(11.364)$ & & & \\
\hline CC122-7-13 & & 1.91 & 6786 & $6102.31(2.65)$ & $0.280(5.958)$ & & & \\
\hline CC122-3 & $845.6(5.0)$ & & & & & 1.5 & $0.9777(0.0011)$ & $0.978(0.014)$ \\
\hline $\mathrm{CC} 122-3-2$ & & 0.88 & 5185 & $7766.37(5.24)$ & $0.122(33.763)$ & & & \\
\hline CC122-3-4 & & 1.38 & 6358 & $6910.68(3.28)$ & $0.202(11.491)$ & & & \\
\hline $\mathrm{CC} 122-3-5$ & & 1.84 & 7474 & $6442.05(2.07)$ & $0.243(5.655)$ & & & \\
\hline $\mathrm{CC} 122-3-6$ & & 1.85 & 7459 & $6426.64(2.17)$ & $0.245(5.896)$ & & & \\
\hline CC122-3-8 & & 1.89 & 6912 & $6103.51(2.01)$ & $0.271(4.719)$ & & & \\
\hline CC122-3-9 & & 1.71 & 6282 & $6165.42(2.31)$ & $0.269(5.512)$ & & & \\
\hline CC122-3-10 & & 1.55 & 5991 & $6315.85(2.66)$ & $0.253(6.897)$ & & & \\
\hline CC122-3-11 & & 1.33 & 5656 & $6663.19(3.67)$ & $0.221(11.431)$ & & & \\
\hline
\end{tabular}




\begin{tabular}{|c|c|c|c|c|c|c|c|c|}
\hline Sample ID & $\begin{array}{l}\text { Depth } \\
\text { from top } \\
(\mathrm{mm}) \\
(100 \% \\
\text { uncert. }) \\
\end{array}$ & $\begin{array}{c}\text { Total } \\
\mathrm{Pb} \\
(\mathrm{ppb})\end{array}$ & $\underset{(\mathrm{ppb})}{\mathrm{U}}$ & $\begin{array}{c}{ }^{238} \mathrm{U} /{ }^{206} \mathrm{~Pb} \\
(2 \sigma \text { error in \%) }\end{array}$ & $\begin{array}{c}{ }^{207} \mathrm{~Pb} /{ }^{206} \mathrm{~Pb} \\
(2 \sigma \text { error in \%) }\end{array}$ & MSWD $^{*}$ & $\begin{array}{l}\left({ }^{234} \mathrm{U} / 238 \mathrm{U}\right)_{\text {measured }} \\
( \pm 95 \% \text { uncertainty })\end{array}$ & $\begin{array}{c}\text { Age (Ma) } \\
\text { corrected for } \\
\left({ }^{234} U / /^{238} U\right)_{\text {initial }} \\
( \pm 2 \sigma \text { error })\end{array}$ \\
\hline \multicolumn{9}{|c|}{ Single-aliquot analyses } \\
\hline $\mathrm{CC} 8-101^{\dagger}$ & $13.0(1.5)$ & 2.38 & 7324 & $6034.62(1.75)$ & $0.363(2.525)$ & n.a. & $0.9779(0.0025)$ & $0.810(0.011)$ \\
\hline CC8-20 & $31.0(3.0)$ & 5.01 & 6390 & $3266.91(0.73)$ & $0.568(0.444)$ & n.a. & $0.9791(0.0015)$ & $0.811(0.012)$ \\
\hline CC8-103 & $40.5(1.5)$ & 2.87 & 10930 & $6747.02(1.90)$ & $0.304(3.655)$ & n.a. & $0.9786(0.0026)$ & $0.817(0.012)$ \\
\hline CC8-19 & $60.5(2.0)$ & 3.72 & 13752 & $6550.50(0.33)$ & $0.325(0.517)$ & n.a. & $0.9772(0.0024)$ & $0.811(0.010)$ \\
\hline CC8-105 & $66.0(1.5)$ & 4.40 & 12310 & $5675.31(1.48)$ & $0.389(1.854)$ & n.a. & $0.9773(0.0023)$ & $0.813(0.012)$ \\
\hline CC8-18 & $87.5(2.0)$ & 2.06 & 11699 & $7968.13(1.03)$ & $0.210(1.330)$ & n.a. & $0.9792(0.0018)$ & $0.816(0.009)$ \\
\hline CC8-108 & $93.0(1.5)$ & 2.91 & 11961 & $6985.91(1.68)$ & $0.284(3.524)$ & n.a. & $0.9809(0.0024)$ & $0.809(0.011)$ \\
\hline CC8-17 & $106.5(2.0)$ & 3.72 & 11175 & $5834.31(0.29)$ & $0.379(0.320)$ & n.a. & $0.9751(0.0014)$ & $0.820(0.007)$ \\
\hline CC8-112 & $127.0(1.5)$ & 3.02 & 10131 & $6263.41(1.32)$ & $0.340(2.031)$ & n.a. & $0.9794(0.0027)$ & $0.813(0.012)$ \\
\hline CC8-114 & $147.0(1.5)$ & 2.71 & 10199 & $6679.37(1.97)$ & $0.304(3.784)$ & n.a. & $0.9809(0.0023)$ & $0.814(0.011)$ \\
\hline CC8-116 & $195.0(1.5)$ & 1.82 & 10210 & $7975.50(1.77)$ & $0.196(6.124)$ & n.a. & $0.9771(0.0024)$ & $0.843(0.012)$ \\
\hline CC8-14 & $207.0(2.0)$ & 3.91 & 9509 & $5083.88(0.29)$ & $0.423(0.306)$ & n.a. & $0.9775(0.0017)$ & $0.836(0.009)$ \\
\hline CC8-119 & $224.0(1.5)$ & 3.66 & 9879 & $5471.18(1.03)$ & $0.394(1.164)$ & n.a. & $0.9801(0.0023)$ & $0.823(0.011)$ \\
\hline CC8-124 & $271.0(1.5)$ & 3.06 & 9957 & $6088.87(1.36)$ & $0.340(2.103)$ & n.a. & $0.9801(0.0023)$ & $0.833(0.012)$ \\
\hline CC8-126 & $286.0(1.5)$ & 3.20 & 8711 & $5531.82(1.94)$ & $0.385(2.542)$ & n.a. & $0.9808(0.0024)$ & $0.828(0.011)$ \\
\hline CC30-2 & $302.6(5.0)$ & 0.85 & 6994 & $9183.65(4.04)$ & $0.075(44.864)$ & n.a. & $0.9857(0.0024)$ & $0.838(0.012)$ \\
\hline CC8-128 & $314.0(1.5)$ & 3.77 & 9183 & $5138.16(1.56)$ & $0.413(1.768)$ & n.a. & $0.9794(0.0023)$ & $0.839(0.013)$ \\
\hline CC $30-3$ & $319.5(5.0)$ & 0.84 & 5855 & $8727.72(4.78)$ & $0.110(34.624)$ & n.a. & $0.9856(0.0024)$ & $0.840(0.012)$ \\
\hline CC8-130 & $325.0(1.5)$ & 3.66 & 9667 & $5432.80(2.31)$ & $0.387(3.042)$ & n.a. & $0.9804(0.0023)$ & $0.841(0.013)$ \\
\hline CC30-4 & $335.1(5.0)$ & 0.80 & 7546 & $9446.60(2.56)$ & $0.055(38.547)$ & n.a. & $0.9855(0.0024)$ & $0.837(0.012)$ \\
\hline CC30-6 & $345.8(5.0)$ & 5.45 & 8812 & $3898.75(2.26)$ & 0.498 (1.817) & n.a. & $0.9863(0.0024)$ & $0.841(0.014)$ \\
\hline CC30-1-1 & $349.9(5.0)$ & 0.72 & 6145 & $9113.62(3.37)$ & $0.068(40.947)$ & n.a. & $0.9874(0.0024)$ & $0.844(0.011)$ \\
\hline CC30-8 & $350.4(5.0)$ & 3.99 & 8015 & $4492.84(1.62)$ & $0.447(1.588)$ & n.a. & $0.9879(0.0025)$ & $0.840(0.012)$ \\
\hline CC30-10 & $352.4(5.0)$ & 7.69 & 8690 & $2953.31(1.14)$ & $0.574(0.605)$ & n.a. & $0.9833(0.0024)$ & $0.856(0.017)$ \\
\hline CC30-12 & $353.9(5.0)$ & 3.04 & 8619 & $5551.27(2.04)$ & $0.358(3.047)$ & n.a. & $0.9868(0.0025)$ & $0.849(0.013)$ \\
\hline CC30-2-12 & $357.1(5.0)$ & 1.24 & 6467 & $7703.26(4.64)$ & $0.180(18.613)$ & n.a. & $0.9840(0.0035)$ & $0.863(0.018)$ \\
\hline CC8-64 & $402.1(2.5)$ & 1.92 & 5372 & $5684.76(4.81)$ & $0.351(7.637)$ & n.a. & $0.9799(0.0014)$ & $0.875(0.013)$ \\
\hline
\end{tabular}




\begin{tabular}{|c|c|c|c|c|c|c|c|c|}
\hline Sample ID & $\begin{array}{l}\text { Depth } \\
\text { from top } \\
(\mathrm{mm}) \\
(100 \% \\
\text { uncert.) }\end{array}$ & $\begin{array}{l}\text { Total } \\
\mathrm{Pb} \\
(\mathrm{ppb})\end{array}$ & $\underset{(\mathrm{ppb})}{\mathrm{U}}$ & $\begin{array}{c}{ }^{238} \mathrm{U} /{ }^{206} \mathrm{~Pb} \\
(2 \sigma \text { error in } \%)\end{array}$ & $\begin{array}{c}{ }^{207} \mathrm{~Pb} /{ }^{206} \mathrm{~Pb} \\
(2 \sigma \text { error in \%) }\end{array}$ & MSWD $^{*}$ & $\begin{array}{c}\left({ }^{234} \mathrm{U}{ }^{238} \mathrm{U}\right)_{\text {measured }} \\
( \pm 95 \% \text { uncertainty })\end{array}$ & $\begin{array}{c}\text { Age (Ma) } \\
\text { corrected for } \\
\left({ }^{234} U /{ }^{238} U\right)_{\text {initial }} \\
( \pm 2 \sigma \text { error })\end{array}$ \\
\hline \multicolumn{9}{|c|}{ Single-aliquot analyses (continued) } \\
\hline CC8-63 & $411.6(2.5)$ & 0.89 & 6321 & $8591.53(2.86)$ & $0.116(19.461)$ & n.a. & $0.9790(0.0016)$ & $0.877(0.010)$ \\
\hline CC8-62 & $416.6(2.5)$ & 1.57 & 7202 & $7109.84(2.64)$ & $0.227(7.950)$ & n.a. & $0.9822(0.0018)$ & $0.876(0.010)$ \\
\hline CC8-87 & $424.6(1.0)$ & 7.02 & 3495 & $4575.96(3.70)$ & $0.440(3.957)$ & n.a. & $0.9807(0.0013)$ & $0.872(0.013)$ \\
\hline CC8-61 & $424.6(2.5)$ & 1.55 & 6709 & $7026.30(3.44)$ & $0.239(9.605)$ & n.a. & $0.9816(0.0014)$ & $0.869(0.009)$ \\
\hline CC8-21 & $428.6(2.0)$ & 3.05 & 9329 & $5676.34(0.45)$ & $0.351(0.688)$ & n.a. & $0.9816(0.0018)$ & $0.868(0.010)$ \\
\hline CC8-60 & $431.6(2.5)$ & 2.06 & 7084 & $6139.49(1.35)$ & $0.313(2.565)$ & n.a. & $0.9810(0.0013)$ & $0.871(0.007)$ \\
\hline $\mathrm{CC} 8-59^{\circ}$ & $435.6(2.5)$ & 2.7 & 6881 & $5187.30(1.47)$ & 0.389 (1.963) & n.a. & $0.9832(0.0012)$ & $0.863(0.008)$ \\
\hline CC8-58 & $437.6(2.5)$ & 1.17 & 6235 & $7578.41(2.09)$ & $0.191(7.855)$ & n.a. & $0.9803(0.0021)$ & $0.881(0.012)$ \\
\hline CC8-86 & $444.6(1.0)$ & 2.14 & 4899 & $5207.73(8.89)$ & $0.386(12.059)$ & n.a. & $0.9820(0.0020)$ & $0.872(0.022)$ \\
\hline CC8-31 & $446.6(2.5)$ & 1.43 & 5956 & $6520.20(2.24)$ & $0.273(4.960)$ & n.a. & $0.9830(0.0018)$ & $0.875(0.010)$ \\
\hline $\mathrm{CC} 119-15^{\mathrm{R}}$ & $451.7(5.0)$ & 10.03 & 5993 & $1753.90(0.81)$ & $0.677(0.277)$ & n.a. & $0.9714(0.0016)$ & $0.884(0.033)$ \\
\hline CC8-85 & $452.6(1.5)$ & 1.98 & 5877 & $5859.68(6.58)$ & $0.312(12.625)$ & n.a. & $0.9853(0.0012)$ & $0.893(0.015)$ \\
\hline CC8-12 & $456.1(2.0)$ & 1.85 & 5934 & $5734.93(0.70)$ & $0.330(1.200)$ & n.a. & $0.9841(0.0019)$ & $0.885(0.010)$ \\
\hline CC119-16 & $457.0(5.0)$ & 4.8 & 6159 & 3309.01 (1.67) & 0.556 (1.059) & n.a. & $0.9712(0.0016)$ & $0.881(0.017)$ \\
\hline CC119-9 & $469.7(5.0)$ & 2.51 & 3239 & $3304.94(2.34)$ & $0.542(1.580)$ & n.a. & $0.9727(0.0030)$ & $0.929(0.028)$ \\
\hline CC8-11 & $478.1(2.0)$ & 2.97 & 6912 & $4750.37(0.35)$ & $0.406(0.402)$ & n.a. & $0.9850(0.0015)$ & $0.895(0.009)$ \\
\hline CC119-17 & $494.2(5.0)$ & 2.13 & 7785 & $6450.2(2.09)$ & $0.299(4.258)$ & n.a. & $0.9741(0.0016)$ & $0.889(0.011)$ \\
\hline CC8-32 & $497.6(2.0)$ & 2.53 & 7631 & $5527.61(0.89)$ & $0.342(1.460)$ & n.a. & $0.9849(0.0012)$ & $0.891(0.007)$ \\
\hline CC119-18 & $513.2(5.0)$ & 8.46 & 8242 & $2633.94(0.94)$ & $0.603(0.475)$ & n.a. & $0.9739(0.0017)$ & $0.892(0.021)$ \\
\hline CC8-10 & $521.6(2.0)$ & 3.42 & 7343 & $4493.98(0.31)$ & $0.423(0.330)$ & n.a. & $0.9869(0.0024)$ & $0.898(0.013)$ \\
\hline CC8-27 & $538.1(3.5)$ & 1.1 & 6124 & $7328.15(1.21)$ & $0.180(4.860)$ & n.a. & $0.9850(0.0014)$ & $0.903(0.008)$ \\
\hline CC119-19R & $554.4(5.0)$ & 10.17 & 5729 & $1654.79(0.67)$ & $0.678(0.228)$ & n.a. & $0.9766(0.0019)$ & $0.898(0.032)$ \\
\hline $\mathrm{CC} 8-33^{\circ}$ & $555.6(2.0)$ & 2.33 & 5101 & $4575.82(0.73)$ & $0.425(0.821)$ & n.a. & 0.9844 (0.0019) & $0.889(0.011)$ \\
\hline CC8-91 & $561.1(2.0)$ & 2.8 & 7769 & $5460.20(3.40)$ & $0.346(5.529)$ & n.a. & $0.9821(0.0010)$ & $0.910(0.010)$ \\
\hline CC119-20 & $561.8(5.0)$ & 0.96 & 4776 & $7514.34(3.77)$ & $0.200(13.390)$ & n.a. & $0.9734(0.0018)$ & $0.919(0.015)$ \\
\hline CC8-34 & $565.1(2.0)$ & 3.37 & 7726 & $4732.16(0.44)$ & $0.415(0.512)$ & n.a. & $0.9803(0.0018)$ & $0.904(0.012)$ \\
\hline CC8-9 & $574.6(2.0)$ & 2.07 & 6653 & $5711.02(0.34)$ & $0.325(0.344)$ & n.a. & $0.9831(0.0020)$ & $0.903(0.012)$ \\
\hline CC119-11 & $584.7(5.0)$ & 2.15 & 6222 & $5661.74(3.02)$ & $0.348(4.860)$ & n.a. & $0.9754(0.0018)$ & $0.911(0.014)$ \\
\hline
\end{tabular}




\begin{tabular}{|c|c|c|c|c|c|c|c|c|}
\hline Sample ID & $\begin{array}{l}\text { Depth } \\
\text { from top } \\
(\mathrm{mm}) \\
(100 \% \\
\text { uncert. })\end{array}$ & $\begin{array}{l}\text { Total } \\
\mathrm{Pb} \\
(\mathrm{ppb})\end{array}$ & $\underset{(\mathrm{ppb})}{\mathrm{U}}$ & $\begin{array}{c}{ }^{238} \mathrm{U} /{ }^{206} \mathrm{~Pb} \\
(2 \sigma \text { error in } \%)\end{array}$ & $\begin{array}{c}{ }^{207} \mathrm{~Pb} /{ }^{206} \mathrm{~Pb} \\
(2 \sigma \text { error in } \%)\end{array}$ & MSWD* $^{*}$ & $\begin{array}{c}\left({ }^{234} \mathrm{U}{ }^{238} \mathrm{U}\right)_{\text {measured }} \\
( \pm 95 \% \text { uncertainty })\end{array}$ & $\begin{array}{c}\text { Age (Ma) } \\
\text { corrected for } \\
\left({ }^{234} U^{238} U\right)_{\text {initial }} \\
( \pm 2 \sigma \text { error })\end{array}$ \\
\hline CC8-29 & $605.1(2.0)$ & 5.88 & 8061 & $3342.69(0.44)$ & $0.527(0.327)$ & n.a. & $0.9837(0.0010)$ & $0.902(0.012)$ \\
\hline CC119-21 & $606.7(5.0)$ & 2.68 & 7236 & $5388.43(1.64)$ & $0.376(2.327)$ & n.a. & $0.9749(0.0016)$ & $0.902(0.012)$ \\
\hline CC8-70 & $632.1(2.5)$ & 1.82 & 6908 & $6354.81(2.02)$ & $0.270(4.763)$ & n.a. & $0.9824(0.0014)$ & $0.907(0.009)$ \\
\hline CC $8-90$ & $634.6(1.5)$ & 1.36 & 7045 & $7664.03(7.38)$ & $0.150(37.392)$ & n.a. & $0.9825(0.0011)$ & $0.919(0.013)$ \\
\hline CC8-69 & $636.1(2.5)$ & 1.83 & 6723 & $6230.14(1.69)$ & $0.280(3.802)$ & n.a. & $0.9815(0.0017)$ & $0.914(0.011)$ \\
\hline CC8-35 & $637.6(2.0)$ & 1.55 & 5412 & $5934.37(1.40)$ & $0.304(2.790)$ & n.a. & $0.9832(0.0013)$ & 0.907 (0.009) \\
\hline CC8-8 & $640.6(2.0)$ & 0.8 & 5972 & $8130.74(0.55)$ & $0.112(3.780)$ & n.a. & $0.9813(0.0022)$ & $0.923(0.014)$ \\
\hline CC8-68 & $646.1(2.5)$ & 1.38 & 5270 & $6439.73(3.77)$ & $0.256(9.625)$ & n.a. & $0.9829(0.0014)$ & $0.916(0.011)$ \\
\hline CC8-67 & $650.1(2.5)$ & 2.19 & 4989 & $4778.54(2.21)$ & $0.398(2.838)$ & n.a. & $0.9824(0.0017)$ & $0.923(0.013)$ \\
\hline CC119-22 & $652.7(7.0)$ & 5.05 & 7862 & $3727.57(0.92)$ & $0.508(0.726)$ & n.a. & $0.9748(0.0020)$ & $0.912(0.017)$ \\
\hline CC119-5 & $652.9(7.0)$ & 1.52 & 6775 & $7064.90(3.11)$ & $0.230(9.143)$ & n.a. & $0.9749(0.0019)$ & $0.919(0.015)$ \\
\hline $\mathrm{CC} 119-12^{\mathrm{R}}$ & $660.1(7.0)$ & 29.16 & 5527 & $605.69(0.30)$ & $0.763(0.054)$ & n.a. & $0.9738(0.0020)$ & $0.938(0.108)$ \\
\hline CC8-66 & $663.6(2.5)$ & 2.04 & 5229 & $5106.22(2.72)$ & $0.357(4.202)$ & n.a. & $0.9854(0.0014)$ & $0.931(0.011)$ \\
\hline $\mathrm{CC} 8-28^{\mathrm{R}}$ & $666.6(2.0)$ & 4.79 & 4061 & $2290.74(0.42)$ & $0.612(0.218)$ & n.a. & $0.9849(0.0025)$ & $0.919(0.022)$ \\
\hline CC8-65 & $667.6(2.5)$ & 1.14 & 4600 & $6538.01(3.69)$ & $0.233(10.698)$ & n.a. & $0.9836(0.0018)$ & $0.936(0.014)$ \\
\hline CC119-23 ${ }^{\mathrm{R}}$ & $674.3(7.0)$ & 11.99 & 7135 & $1729.74(0.56)$ & $0.671(0.197)$ & n.a. & $0.9748(0.0016)$ & $0.920(0.031)$ \\
\hline $\mathrm{CC} 119-24^{\mathrm{R}}$ & $682.2(5.0)$ & 17.46 & 5819 & $1027.67(0.38)$ & $0.727(0.094)$ & n.a. & $0.9757(0.0014)$ & $0.930(0.057)$ \\
\hline CC8-79 & $686.6(1.5)$ & 1.38 & 5129 & $6353.80(6.24)$ & $0.232(18.218)$ & n.a. & $0.9874(0.0014)$ & $0.943(0.014)$ \\
\hline CC119-25 & $693.8(5.0)$ & 4.18 & 5768 & $3421.23(1.50)$ & $0.527(1.082)$ & n.a. & $0.9754(0.0019)$ & $0.931(0.020)$ \\
\hline $\mathrm{CC} 122-15^{\mathrm{R}}$ & $699.3(5.0)$ & 18.4 & 6762 & $1123.09(0.40)$ & $0.719(0.106)$ & n.a. & $0.9760(0.0015)$ & $0.935(0.052)$ \\
\hline $\mathrm{CC} 122-16^{\mathrm{R}}$ & $704.5(5.0)$ & 10.24 & 6410 & $1818.96(1.51)$ & $0.659(0.571)$ & n.a. & $0.9753(0.0019)$ & $0.947(0.033)$ \\
\hline $\mathrm{CC} 119-13^{\mathrm{R}}$ & $707.4(5.0)$ & 25.47 & 6412 & $791.91(0.41)$ & $0.746(0.088)$ & n.a. & $0.9746(0.0019)$ & $0.950(0.082)$ \\
\hline $\mathrm{CC} 122-8^{\mathrm{R}}$ & $717.6(5.0)$ & 11.57 & 7201 & $1794.34(0.73)$ & $0.661(0.274)$ & n.a. & $0.9755(0.0017)$ & $0.946(0.034)$ \\
\hline CC8-38 & $719.6(2.5)$ & 2.49 & 5651 & $4676.79(2.72)$ & $0.382(3.752)$ & n.a. & $0.9889(0.0021)$ & $0.941(0.015)$ \\
\hline $\mathrm{CC} 122-17^{\mathrm{R}}$ & $736.9(5.0)$ & 11.6 & 5147 & $1335.02(0.80)$ & $0.699(0.239)$ & n.a. & $0.9763(0.0016)$ & $0.951(0.043)$ \\
\hline CC122-18 & $755.0(5.0)$ & 7.3 & 7032 & $2565.03(0.78)$ & $0.592(0.414)$ & n.a. & $0.9770(0.0016)$ & $0.952(0.022)$ \\
\hline CC $8-40$ & $759.6(2.5)$ & 4.63 & 4595 & $3651.10(1.58)$ & $0.485(0.992)$ & n.a. & $0.9844(0.0017)$ & $0.946(0.014)$ \\
\hline $\mathrm{CC} 122-9^{\mathrm{R}}$ & $765.8(5.0)$ & 22.38 & 7157 & $986.09(0.40)$ & $0.727(0.097)$ & n.a. & $0.9763(0.0025)$ & $0.979(0.068)$ \\
\hline $\mathrm{CC} 122-19^{\mathrm{R}}$ & $773.9(5.0)$ & 9.04 & 7390 & $2242.67(0.70)$ & $0.619(0.326)$ & n.a. & $0.9766(0.0016)$ & $0.964(0.027)$ \\
\hline CC8-75 & $774.6(1.5)$ & 2.93 & 4922 & $3953.69(4.80)$ & $0.453(4.839)$ & n.a. & $0.9870(0.0019)$ & $0.942(0.018)$ \\
\hline
\end{tabular}




\begin{tabular}{|c|c|c|c|c|c|c|c|c|}
\hline Sample ID & $\begin{array}{l}\text { Depth } \\
\text { from top } \\
(\mathrm{mm}) \\
(100 \% \\
\text { uncert.) }\end{array}$ & $\begin{array}{l}\text { Total } \\
\mathrm{Pb} \\
(\mathrm{ppb})\end{array}$ & $\underset{(\mathrm{ppb})}{\mathrm{U}}$ & $\begin{array}{c}{ }^{238} \mathrm{U}^{206} \mathrm{~Pb} \\
(2 \sigma \text { error in \%) }\end{array}$ & $\begin{array}{c}{ }^{207} \mathrm{~Pb} /{ }^{206} \mathrm{~Pb} \\
(2 \sigma \text { error in \%) }\end{array}$ & MSWD $^{*}$ & $\begin{array}{c}\left({ }^{234} \mathrm{U} /{ }^{238} \mathrm{U}\right)_{\text {measured }} \\
( \pm 95 \% \text { uncertainty })\end{array}$ & $\begin{array}{c}\text { Age (Ma) } \\
\text { corrected for } \\
\left({ }^{234} U /{ }^{238} U\right)_{\text {initial }} \\
( \pm 2 \sigma \text { error })\end{array}$ \\
\hline $\mathrm{CC} 122-10^{\mathrm{R}}$ & $782.5(5.0)$ & 9.99 & 7764 & $2145.99(0.58)$ & $0.625(0.263)$ & n.a. & $0.9770(0.0017)$ & $0.975(0.029)$ \\
\hline CC8-74 & $785.6(2.0)$ & 4.98 & 4815 & $2567.49(1.69)$ & $0.580(0.961)$ & n.a. & $0.9863(0.0022)$ & $0.943(0.021)$ \\
\hline CC8-6 & $791.6(2.0)$ & 1.38 & 4454 & $5471.66(0.87)$ & $0.298(1.770)$ & n.a. & $0.9887(0.0011)$ & $0.962(0.008)$ \\
\hline $\mathrm{CC} 122-20^{\mathrm{R}}$ & $793.7(5.0)$ & 12.53 & 7109 & $1643.56(0.64)$ & $0.667(0.228)$ & n.a. & $0.9751(0.0016)$ & $1.015(0.042)$ \\
\hline CC8-57 & $794.1(2.5)$ & 1.55 & 5677 & $5983.79(2.25)$ & $0.253(5.820)$ & n.a. & $0.9896(0.0019)$ & $0.950(0.013)$ \\
\hline CC122-21 & $796.0(5.0)$ & 3 & 7592 & $5055.91(2.23)$ & $0.371(3.233)$ & n.a. & $0.9792(0.0029)$ & $0.953(0.023)$ \\
\hline CC8-54 & $798.6(2.5)$ & 1.61 & 5652 & $5400.31(1.66)$ & $0.307(3.251)$ & n.a. & $0.9884(0.0022)$ & $0.960(0.014)$ \\
\hline CC $8-42$ & $799.6(2.0)$ & 2.19 & 5708 & $4880.67(0.96)$ & $0.355(1.490)$ & n.a. & $0.9885(0.0017)$ & $0.960(0.012)$ \\
\hline $\mathrm{CC} 122-12^{\mathrm{R}}$ & $799.6(5.0)$ & 14.81 & 8091 & $1586.74(0.47)$ & $0.671(0.162)$ & n.a. & $0.9757(0.0018)$ & $1.018(0.044)$ \\
\hline $\mathrm{CC} 8-73$ & $801.1(2.0)$ & 2.77 & 6072 & $4648.23(5.22)$ & $0.375(7.428)$ & n.a. & $0.9875(0.0016)$ & $0.971(0.017)$ \\
\hline $\mathrm{CC} 8-53$ & $802.6(2.5)$ & 1.34 & 5473 & $6277.53(1.90)$ & $0.227(5.708)$ & n.a. & $0.9891(0.0021)$ & $0.952(0.013)$ \\
\hline CC122-22 & $802.9(5.0)$ & 1.79 & 8035 & $6793.83(2.24)$ & $0.218(7.061)$ & n.a. & $0.9781(0.0028)$ & $0.961(0.024)$ \\
\hline CC8-72 & $811.6(1.5)$ & 2.27 & 6022 & $5235.76(6.51)$ & $0.313(12.425)$ & n.a. & $0.9906(0.0017)$ & $0.965(0.017)$ \\
\hline CC8-71 & $817.6(1.5)$ & 2.67 & 5046 & $4165.55(3.33)$ & $0.421(3.859)$ & n.a. & $0.9879(0.0019)$ & $0.968(0.016)$ \\
\hline CC8-56 & $821.1(2.5)$ & 2.17 & 4705 & $4487.73(2.53)$ & $0.387(3.424)$ & n.a. & $0.9892(0.0010)$ & $0.968(0.010)$ \\
\hline CC8-43 & $826.1(2.5)$ & 4.05 & 6109 & $6137.32(1.79)$ & $0.230(4.500)$ & n.a. & $0.9912(0.0014)$ & 0.957 (0.009) \\
\hline CC8-5 & $832.1(2.0)$ & 1.76 & 5427 & $5534.28(4.02)$ & $0.285(8.790)$ & n.a. & $0.9908(0.0012)$ & $0.962(0.011)$ \\
\hline CC8-52 & $836.6(2.5)$ & 1.46 & 6094 & $6353.26(3.41)$ & $0.206(11.650)$ & n.a. & $0.9900(0.0016)$ & $0.968(0.011)$ \\
\hline CC8-51 & $840.1(2.5)$ & 1.27 & 5983 & $6617.00(2.36)$ & $0.184(9.333)$ & n.a. & $0.9899(0.0012)$ & $0.964(0.009)$ \\
\hline CC122-24R & $854.6(5.0)$ & 12.64 & 8155 & $1835.31(0.90)$ & $0.647(0.360)$ & n.a. & $0.9775(0.0016)$ & $1.007(0.034)$ \\
\hline $\mathrm{CC} 122-14^{\mathrm{R}}$ & $858.6(5.0)$ & 10.19 & 8246 & $2216.07(0.97)$ & $0.613(0.466)$ & n.a. & $0.9784(0.0019)$ & $0.994(0.028)$ \\
\hline
\end{tabular}

Notes:

$¥$ Age-sample depths are given on the composite depth scale.

${ }^{*}$ MSWD = mean square weighted deviation, calculated by Isoplot (65) based upon the assumptions of a model 1 or 2 fit.

$\S$ Only one new isochron age for CC8 is presented here; the other seven isochron ages were presented in ref. 22.

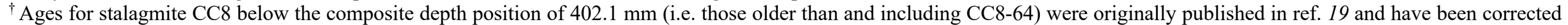

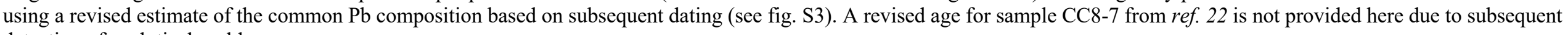
detection of analytical problems.

${ }^{\mathrm{O}}$ Rejected as outlier (shown in grey).

${ }^{\mathrm{R}}$ Rejected due to low-radiogenic composition of the sample $\left({ }^{238} \mathrm{U} /{ }^{206} \mathrm{~Pb}<2500\right)$ (shown in grey). 
Table S2._Comparison of sedimentation rates for Site U1385. Data are derived from previously published age models (30) and the age models generated from this study. The 'DH2015 Oxy' is based on tuning to the LR04 benthic stack; 'DH2015 Orbital' is based on tuning the sediment lightness series to orbital precession; 'DH2015 GLSyn' is based on tuning to the Greenland synthetic time series (66); and 'DH2015 ${ }^{14} \mathrm{C}$ ' is based on radiocarbon ages. The minimum rates shown for all DH models except DH2015 ${ }^{14} \mathrm{C}$ exclude a section through late MIS12 to early MIS11 where a hiatus is suspected - see ref. 30. For the models generated from this study, 'CC-Raw' is an interpolation of the Corchia U-Pb age model through the 80 age-control points, and is free of any sedimentation rate constraints; the 'CC-Bacon' is produced from the Bacon for $R$ software (56) and used a mean sedimentation rate constraint of $0.1 \mathrm{~m}$ $\mathrm{kyr}^{-1}$; and ' $\mathrm{CC}-\mathrm{FGR}$ ' is calculated using the finite growth-rate age modelling procedure used in the Corchia U-Pb age model with growth rate allowed to vary by a factor of \pm 3 . The ' $\%$ difference' is the percentage difference of the age offset between CC-Raw and CC-Bacon, or CC-Raw and CC-FGR, and the corresponding error envelope for CC-Raw. Note also that the age uncertainties for both the CC-Bacon and CC-FGR models are not used to provide the final age uncertainty estimates for the start of both terminations because the input uncertainties from the CC-1385 tie points are correlated and cannot be considered independently as assumed by these models.

\begin{tabular}{|c|c|c|c|c|c|c|c|}
\hline & $\begin{array}{c}\text { DH2015 } \\
\text { Oxy }^{\dagger}\end{array}$ & $\begin{array}{l}\text { DH2015 } \\
\text { Orbital }^{\dagger}\end{array}$ & $\begin{array}{l}\text { DH2015 } \\
\text { GLSyn }^{\#}\end{array}$ & $\begin{array}{c}\text { DH2015 } \\
{ }^{14} C^{\S}\end{array}$ & CC-Raw ${ }^{¥}$ & $\begin{array}{c}\text { CC-Bacon } \\
\text { for } \mathbf{R}^{¥}\end{array}$ & CC-FGR ${ }^{\sharp}$ \\
\hline \multicolumn{8}{|c|}{ Sedimentation rate $\left(\mathrm{m} \mathrm{kyr}^{-1}\right)$} \\
\hline Minimum & 0.03 & 0.06 & 0.04 & 0.13 & 0.02 & 0.04 & 0.03 \\
\hline Maximum & 0.26 & 0.22 & 0.33 & 0.35 & 0.86 & 0.29 & 0.26 \\
\hline Mean & 0.12 & 0.12 & 0.13 & 0.20 & 0.15 & 0.11 & 0.12 \\
\hline \multicolumn{8}{|c|}{ Termination age (ka) $\pm 2 \sigma$} \\
\hline Start of $\mathrm{TX}^{\&}$ & 874.3 & 873.9 & n.a. & n.a. & $\begin{array}{c}875.4 \\
+2.9 /-4.3 \\
\end{array}$ & $\begin{array}{c}876.3 \\
+1.9 /-2.0 \\
\end{array}$ & $\begin{array}{c}875.7 \\
+2.1 /-1.8 \\
\end{array}$ \\
\hline Start of TX* & & & & & $875.4 \pm 4.7$ & $876.3 \pm 2.8$ & $875.7 \pm 2.9$ \\
\hline$\%$ difference & n.a. & n.a. & n.a. & n.a. & & 12.4 & 3.4 \\
\hline Start of TXII\& & 961.5 & 962.0 & n.a. & n.a. & $\begin{aligned} & 960.1 \\
+ & 4.3 /-3.0\end{aligned}$ & $\begin{array}{c}960.1 \\
+1.8 /-1.7\end{array}$ & $\begin{array}{c}960.7 \\
+1.4 /-1.1\end{array}$ \\
\hline Start of TXII* & & & & & $960.1 \pm 4.7$ & $960.1 \pm 2.7$ & $960.7 \pm 2.4$ \\
\hline$\%$ difference & n.a. & n.a. & n.a. & n.a. & n.a. & 0.5 & 8.4 \\
\hline
\end{tabular}

Notes:

$\uparrow$ Based on an age model for the entire core depth (30)

\# Based on an age model for the period 0-800 ka $(30,66)$

$\S$ Based on an age model for the period 0-28 ka (30)

$¥$ From this study

\& Uncertainty estimate based on age modelling only

* Age-modelling and synchronization uncertainties combined in quadrature

$\$$ Difference between the CC-Raw and CC-Bacon or CC-FGR ages as a percentage of the CC-Raw age-uncertainty envelope (excludes the synchronization uncertainty) 
Table S3. LR04 benthic $\delta^{18} \mathrm{O}$ marker points used to identifying the start and end of Terminations IIIa to VII. The starting points were chosen based on their alignment with the ODP980 (TIIIa to TIV) and U1314 (TV to TVII) benthic $\delta^{18} \mathrm{O}$ values that mark the start of each terminal Heinrich event (see Materials and Methods). The ages shown here are the unadjusted ages based on two different LR04 age models: the original (5) and a depth-derived model (17). (NB: the corresponding ages for TI and TII were radiometrically derived directly from ref. 63 and ref. 64 respectively; ages for TX and TXII are from this study.

\begin{tabular}{|c|c|c|c|c|c|c|}
\hline $\begin{array}{l}\text { Term. } \\
\text { number }\end{array}$ & $\begin{array}{c}\text { LR04 benthic } \delta^{18} O \\
\text { value at start of } \\
\text { termination }\end{array}$ & $\begin{array}{c}\text { Original LR04 } \\
\text { benthic age (ka) }\end{array}$ & $\begin{array}{l}\text { Huybers (2006) } \\
\text { LR04 benthic age } \\
\text { (ka) }\end{array}$ & $\begin{array}{l}\text { LR04 benthic } \delta^{18} \mathrm{O} \\
\text { value at end of } \\
\text { termination }\end{array}$ & $\begin{array}{c}\text { Original LR04 } \\
\text { benthic age (ka) }\end{array}$ & $\begin{array}{l}\text { Huybers (2006) } \\
\text { LR04 benthic age } \\
\text { (ka) }\end{array}$ \\
\hline I & n.a. & n.a. & n.a. & n.a. & n.a. & n.a. \\
\hline II & n.a. & n.a. & n.a. & n.a. & n.a. & n.a. \\
\hline IIIa & 4.410 & 222.5 & 211.2 & 3.505 & 216.5 & 205.6 \\
\hline III & 4.540 & 250.5 & 237.8 & 3.440 & 239.5 & 226.9 \\
\hline IV & 4.815 & 342.5 & 329.8 & 3.210 & 328.5 & 313.1 \\
\hline $\mathrm{V}$ & 5.015 & 430.5 & 425.9 & 3.185 & 409.5 & 405.3 \\
\hline VI & 4.485 & 537.5 & 539.6 & 3.945 & 530.5 & 535.2 \\
\hline VIIa & 4.300 & 583.5 & 584.2 & 3.425 & 575.5 & 576.5 \\
\hline VII & 4.955 & 627.0 & 625.9 & 3.525 & 613.0 & 613.1 \\
\hline $\mathrm{X}$ & n.a. & n.a. & n.a. & n.a. & n.a. & n.a. \\
\hline XII & n.a. & n.a. & n.a. & n.a. & n.a. & n.a. \\
\hline
\end{tabular}


Table S4a. Termination timing and spacing, and the prevailing astronomical and insolation metrics (see Materials and Methods for explanation). The timing of the termination completions for TIII to TVII are based on the control points from the LR04 benthic $\delta^{18} \mathrm{O}$ (Table S3); the remaining completion ages have been derived radiometrically (63, 64; this study). The TIIIa to TVII completion ages are based on the original LR04 age model (4), and have been adjusted according to the radiometric age estimates for the termination start. The 'Obl.' and 'Prec.' columns are derived by dividing the spacing in kyr by the nearest whole number of obliquity or precession cycles. The mean values shown in bold at the base of the table are the averages \pm one standard deviation of these column values. For the phase lead (final column), $360^{\circ}$ was added to the two values of obliquity that are beyond zero phase; values where termination onsets show a precession lead (i.e. negative) are italicised.

\begin{tabular}{|c|c|c|c|c|c|c|c|c|c|c|c|c|c|c|c|c|c|c|c|c|c|c|c|c|c|c|}
\hline \multirow{3}{*}{$\begin{array}{c}\text { Term. } \\
\text { number }\end{array}$} & \multirow{2}{*}{\multicolumn{4}{|c|}{$\begin{array}{c}\text { Termination age (ka) and } \\
\text { duration (kyr) }\end{array}$}} & \multicolumn{3}{|c|}{$\begin{array}{c}\text { Termination spacing at } \\
\text { midpoint (kyr) }\end{array}$} & \multicolumn{6}{|c|}{ Astronomical metrics } & \multicolumn{6}{|c|}{ Insolation metrics (at $65^{\circ} \mathrm{N}$ ) } & \multicolumn{6}{|c|}{ Astronomical phasing $\left(^{\circ}\right)$} & \multirow{3}{*}{$\begin{array}{c}\text { Phase } \\
\text { lead } \\
\text { (obl. } \\
\text { minus } \\
\text { prec.) } \\
\text { at } \\
\text { start }\end{array}$} \\
\hline & & & & & \multirow{2}{*}{$\begin{array}{c}\text { Spac- } \\
\text { ing }\end{array}$} & \multirow{2}{*}{ Obl. } & \multirow{2}{*}{ Prec. } & \multicolumn{3}{|c|}{ Obliquity $\left({ }^{\circ}\right)$} & \multicolumn{3}{|c|}{ Precession index } & \multicolumn{3}{|c|}{ Cal. sum. half-yr insol. } & \multicolumn{3}{|c|}{ Integrated sum. insol. } & \multicolumn{3}{|c|}{ Obliquity } & \multicolumn{3}{|c|}{ Precession } & \\
\hline & Start & Mid & End & Dur. & & & & Start & Mid & End & Start & Mid & End & Start & Mid & End & Start & Mid & End & Start & Mid & End & Start & Mid & End & \\
\hline I & 18 & 12.5 & 7 & 11 & 120 & 40.0 & 24.0 & 23.48 & 24.13 & 24.16 & 0.006 & -0.019 & -0.006 & 5.84 & 6.03 & 5.99 & 5.04 & 5.20 & 5.18 & 282 & 332 & 23 & 249 & 343 & 77 & 33 \\
\hline II & 136 & 132.5 & 129 & 7 & 85.5 & 42.8 & 21.4 & 23.97 & 24.23 & 24.21 & 0.027 & -0.005 & -0.036 & 5.84 & 6.00 & 6.10 & 5.09 & 5.19 & 5.25 & 313 & 346 & 19 & 225 & 278 & 330 & 88 \\
\hline IIIa & 221 & 218 & 215 & 6 & 26.5 & & 26.5 & 23.64 & 24.12 & 24.41 & -0.048 & -0.038 & -0.003 & 6.04 & 6.09 & 6.03 & 5.18 & 5.24 & 5.22 & 284 & 313 & 341 & 344 & 33 & 82 & -59 \\
\hline III & 250 & 244.5 & 239 & 11 & 91.5 & 45.8 & 22.9 & 24.36 & 23.74 & 22.73 & 0.018 & -0.029 & -0.027 & 5.94 & 6.01 & 5.87 & 5.18 & 5.15 & 4.97 & 18 & 68 & 117 & 229 & 319 & 49 & 149 \\
\hline IV & 343 & 336 & 329 & 14 & 84.5 & 42.3 & 21.1 & 23.26 & 24.18 & 24.07 & 0.018 & -0.028 & 0.003 & 5.74 & 6.06 & 5.95 & 4.97 & 5.23 & 5.15 & 265 & 332 & 38 & 216 & 342 & 98 & 49 \\
\hline $\mathrm{V}$ & 431 & 420.5 & 410 & 21 & 111 & 37.0 & 22.2 & 22.78 & 24.13 & 23.86 & -0.005 & 0.011 & -0.015 & 5.78 & 5.91 & 5.98 & 4.93 & 5.15 & 5.15 & 234 & 329 & 57 & 300 & 150 & 342 & -66 \\
\hline VI & 535 & 531.5 & 528 & 7 & 50.5 & 50.5 & 25.3 & 24.18 & 23.93 & 23.52 & -0.004 & -0.010 & -0.014 & 6.00 & 5.98 & 5.94 & 5.19 & 5.15 & 5.09 & 18 & 50 & 81 & 290 & 325 & 0 & 88 \\
\hline VIIa & 586 & 582 & 578 & 8 & 44 & 44.0 & 22.0 & 23.74 & 24.00 & 24.07 & 0.026 & -0.023 & -0.043 & 5.80 & 6.02 & 6.09 & 5.05 & 5.19 & 5.24 & 303 & 336 & 8 & 229 & 295 & 0 & 74 \\
\hline VII & 633 & 626 & 619 & 14 & & & & 23.19 & 23.74 & 23.84 & 0.021 & -0.011 & -0.025 & 5.73 & 5.93 & 6.02 & 4.96 & 5.12 & 5.16 & 246 & 18 & 27 & 180 & 36 & 54 & 66 \\
\hline $\mathrm{x}$ & 875 & 870 & 865 & 10 & 88.5 & 44.5 & 22.3 & 23.61 & 23.75 & 23.68 & 0.037 & -0.002 & -0.038 & 5.72 & 5.90 & 6.03 & 5.00 & 5.10 & 5.16 & 309 & 351 & 31 & 196 & 278 & 0 & 112 \\
\hline XII & 960 & 958.5 & 957 & 3 & & & & 23.79 & 23.85 & 23.90 & -0.050 & -0.055 & -0.050 & 6.05 & 6.09 & 6.09 & 5.21 & 5.23 & 5.23 & 319 & 331 & 344 & 327 & 352 & 18 & -8 \\
\hline
\end{tabular}


Extended Data Table 4b. Same as for Table S4a except that the ref. 17 depth-derived age model is used for TIIIa to TVII instead of the original LR04 age model (4).

\begin{tabular}{|c|c|c|c|c|c|c|c|c|c|c|c|c|c|c|c|c|c|c|c|c|c|c|c|c|c|}
\hline \multirow{3}{*}{$\begin{array}{c}\text { Term. } \\
\text { number }\end{array}$} & \multirow{2}{*}{\multicolumn{4}{|c|}{$\begin{array}{l}\text { Termination age (ka) and } \\
\quad \text { duration }(\mathbf{k y r})\end{array}$}} & \multicolumn{3}{|c|}{$\begin{array}{l}\text { Termination spacing at } \\
\text { midpoint (kyr) }\end{array}$} & \multicolumn{6}{|c|}{ Astronomical metrics } & \multicolumn{6}{|c|}{ Insolation metrics (at $65^{\circ} \mathrm{N}$ ) } & \multicolumn{6}{|c|}{ Astronomical phasing $\left({ }^{\circ}\right)$} \\
\hline & & & & & \multirow{2}{*}{$\begin{array}{c}\text { Spac- } \\
\text { ing }\end{array}$} & \multirow{2}{*}{ Obl. } & \multirow{2}{*}{ Prec. } & \multicolumn{3}{|c|}{ Obliquity $\left({ }^{\circ}\right)$} & \multicolumn{3}{|c|}{ Precession index } & \multicolumn{3}{|c|}{ Cal. sum. half-yr insol. } & \multicolumn{3}{|c|}{ Integrated sum. insol. } & \multicolumn{3}{|c|}{ Obliquity } & \multicolumn{3}{|c|}{ Precession } \\
\hline & Start & Mid & End & Dur. & & & & Start & Mid & End & Start & Mid & End & Start & Mid & End & Start & Mid & End & Start & Mid & End & Start & Mid & End \\
\hline I & 18 & 12.5 & 7 & 11 & 120 & 40.0 & 24.0 & 23.48 & 24.13 & 24.16 & 0.010 & -0.019 & -0.006 & 5.84 & 6.03 & 5.99 & 5.04 & 5.20 & 5.18 & 282 & 332 & 23 & 249 & 343 & 77 \\
\hline II & 136 & 132.5 & 129 & 7 & 85.7 & 42.9 & 21.4 & 23.97 & 24.23 & 24.21 & 0.030 & -0.005 & -0.036 & 5.84 & 6.00 & 6.10 & 5.09 & 5.19 & 5.25 & 313 & 346 & 19 & 225 & 278 & 330 \\
\hline IIIa & 221 & 218.2 & 215.4 & 5.6 & 27.3 & 27.3 & 27.3 & 23.64 & 24.09 & 24.38 & -0.050 & -0.039 & -0.008 & 6.04 & 6.09 & 6.04 & 5.18 & 5.24 & 5.23 & 284 & 311 & 337 & 344 & 30 & 75 \\
\hline III & 250 & 245.5 & 239.1 & 10.9 & 89.2 & 44.6 & 22.3 & 24.36 & 23.74 & 22.75 & 0.020 & -0.029 & -0.028 & 5.94 & 6.01 & 5.87 & 5.18 & 5.15 & 4.98 & 18 & 68 & 116 & 229 & 319 & 48 \\
\hline IV & 343 & 334.7 & 326.3 & 16.7 & 86 & 43.0 & 21.5 & 23.26 & 24.25 & 23.76 & 0.020 & -0.030 & 0.025 & 5.74 & 6.08 & 5.81 & 4.97 & 5.25 & 5.05 & 265 & 344 & 38 & 216 & 5 & 98 \\
\hline $\mathrm{V}$ & 431 & 420.7 & 410.3 & 20.7 & 112.5 & 37.5 & 22.5 & 22.78 & 24.12 & 23.89 & 0.000 & 0.011 & -0.014 & 5.78 & 5.91 & 5.98 & 4.93 & 5.15 & 5.15 & 234 & 327 & 57 & 300 & 146 & 342 \\
\hline VI & 535 & 533.4 & 530.6 & 4.4 & 49 & 49.0 & 24.5 & 24.18 & 24.04 & 23.83 & 0.000 & -0.008 & -0.012 & 6.00 & 5.98 & 5.97 & 5.19 & 5.17 & 5.14 & 18 & 38 & 58 & 290 & 312 & 334 \\
\hline VIIa & 586 & 582.2 & 578.3 & 7.7 & 44.4 & 44.4 & 22.2 & 23.74 & 23.99 & 24.07 & 0.030 & -0.021 & -0.043 & 5.80 & 6.01 & 6.09 & 5.05 & 5.18 & 5.24 & 303 & 334 & 6 & 229 & 291 & 355 \\
\hline VII & 633 & 626.6 & 620.2 & 12.8 & & & & 23.19 & 23.70 & 23.87 & 0.020 & -0.006 & -0.031 & 5.73 & 5.91 & 6.04 & 4.96 & 5.10 & 5.18 & 246 & 327 & 45 & 180 & 308 & 90 \\
\hline $\mathrm{x}$ & 875 & 869.5 & 864 & 10 & 89 & 44.5 & 22.3 & 23.61 & 23.75 & 23.68 & 0.037 & -0.002 & -0.038 & 5.72 & 5.90 & 6.03 & 5.00 & 5.10 & 5.16 & 309 & 351 & 31 & 196 & 278 & 0 \\
\hline XII & 960 & 958.5 & 957 & 3 & & & & 23.79 & 23.85 & 23.90 & -0.050 & -0.055 & -0.050 & 6.05 & 6.09 & 6.09 & 5.21 & 5.23 & 5.23 & 319 & 331 & 344 & 327 & 352 & 18 \\
\hline
\end{tabular}

$\begin{array}{lll}\text { Mean } & 41 \pm 7 \quad 23 \pm 2\end{array}$ 